\title{
Experimental investigation of the mechanical properties of synthetic magnesium sulfate hydrates: Implications for the strength of hydrated deposits on Mars
}

\author{
Peter M. Grindrod, ${ }^{1,2}$ Michael J. Heap, ${ }^{1,3}$ A. Dominic Fortes, ${ }^{1,2}$ Philip G. Meredith, ${ }^{1}$
} Ian G. Wood, ${ }^{1}$ Fabio Trippetta, ${ }^{4}$ and Peter R. Sammonds ${ }^{1}$

Received 23 November 2009; revised 19 January 2010; accepted 1 February 2010; published 24 June 2010.

[1] We have carried out uniaxial compression experiments to determine the mechanical properties of three crystalline magnesium sulfate hydrates that may be present in the near-surface environment of Mars. Our synthetic samples of kieserite $\left(\mathrm{MgSO}_{4} \cdot \mathrm{H}_{2} \mathrm{O}\right)$, epsomite $\left(\mathrm{MgSO}_{4} \cdot 7 \mathrm{H}_{2} \mathrm{O}\right)$, and meridianiite $\left(\mathrm{MgSO}_{4} \cdot 11 \mathrm{H}_{2} \mathrm{O}\right)$ have mean values of unconfined compressive strength of $6.3 \pm 0.7,12.9 \pm 1.8$, and $30.1 \pm 4.5 \mathrm{MPa}$, respectively, Young's modulus of $0.8 \pm 0.1,2.9 \pm 0.4$, and $5.9 \pm 0.8 \mathrm{GPa}$, respectively, and mean porosity values of $47.8 \% \pm 0.5 \%, 11.1 \% \pm 0.6 \%$, and $2.9 \% \pm 0.2 \%$, respectively. Although our tests cannot quantify a systematic relationship between hydration state and mechanical properties, the different porosities produced by consistent sample preparation methods suggest that the addition of non-cation-coordinated water molecules likely reduces the strength of individual sulfate hydrate phases. However, the bulk mechanical properties of our synthetic specimens are instead controlled predominantly by the sample porosity; generally, the strength increases as the porosity decreases. We expect the mechanical properties of sulfate hydrate deposits on Mars to be governed by the bulk porosity rather than the strength of the pure solid phase. We have performed cyclic stressing tests, replicating possible periodic depositional and erosional periods on Mars resulting from obliquity changes. A gradual compaction and reduction in sample porosity, rather than an increase in crack damage, is observed with each loading cycle, suggesting that the evolution of mechanical properties will depend on local factors such as bulk density, in addition to the overall stress history.

Citation: Grindrod, P. M., M. J. Heap, A. D. Fortes, P. G. Meredith, I. G. Wood, F. Trippetta, and P. R. Sammonds (2010), Experimental investigation of the mechanical properties of synthetic magnesium sulfate hydrates: Implications for the strength of hydrated deposits on Mars, J. Geophys. Res., 115, E06012, doi:10.1029/2009JE003552.

\section{Introduction}

[2] The present stable phase of water on Mars is in the form of ice. Large volumes of water ice exist permanently in the northern [Kieffer et al., 1976] and southern [Titus et al., 2003] polar ice caps, which extend poleward from latitudes of $80^{\circ}$ [e.g., Clifford et al., 2000]. Subsurface ice is likely at lower latitudes [Boynton et al., 2002], with theoretical studies of permafrost stability predicting that ice may be stable even in near-equatorial regions during periods of high \footnotetext{
UK.

${ }^{1}$ Department of Earth Sciences, University College London, London, ${ }^{2}$ UK.

${ }^{2}$ Centre for Planetary Sciences, University College London, London,

${ }^{3}$ Department of Earth and Environmental Sciences, Section for Mineralogy, Petrology and Geochemistry, Ludwig-MaximiliansUniversity Munich, Munich, Germany.

${ }^{4}$ Dipartimento di Scienze della Terra, Università degli Studi di Perugia, Perugia, Italy.

Copyright 2010 by the American Geophysical Union. 0148-0227/10/2009JE003552
}

obliquity [Mellon et al., 1997]. Neutron and gamma-ray spectroscopy has revealed hydrogen-rich near-surface $(<1 \mathrm{~m})$ soil that generally correlates with the predicted stability of water ice [Feldman et al., 2004], indicating an average subsurface layer that may be $\sim 60 \%$ ice by volume [Boynton et al., 2002]. There is also indirect mineralogical evidence of water: the iron oxide hematite $\left(\mathrm{Fe}_{2} \mathrm{O}_{3}\right)$, which often forms in standing water, has been identified from orbit by the Thermal Emission Spectrometer onboard Mars Global Surveyor [Christensen et al., 2000] and the Observatoire pour la Mineralogie, l'Eau, les Glaces et l'Activité (OMEGA) instrument onboard Mars Express [Gendrin et al., 2005]. The presence, and likely water-borne formation, of hematite was recently confirmed in situ by the Mars Exploration Rover Opportunity in Meridiani Planum [e.g., Squyres et al., 2004].

[3] However, a considerable volume of water is probably also locked up in a range of crystalline hydrates, which are important water reservoirs where ice is not stable at the surface. Orbital observations at near-infrared wavelengths 
have revealed an abundance of hydrated sulfate minerals. OMEGA has identified hydrated minerals, including gypsum $\left(\mathrm{CaSO}_{4} \cdot 2 \mathrm{H}_{2} \mathrm{O}\right)$, kieserite $\left(\mathrm{MgSO}_{4} \cdot \mathrm{H}_{2} \mathrm{O}\right)$, epsomite $\left(\mathrm{MgSO}_{4} \cdot 7 \mathrm{H}_{2} \mathrm{O}\right)$, and some Fe sulfates at a range of latitudes [Gendrin et al., 2005; Horgan et al., 2009]. These deposits are most common in canyons in Valles Marineris, often in association with light-toned deposits [Gendrin et al., 2005]. Recent high spatial resolution observations by the Compact Reconnaissance Imaging Spectrometer for Mars (CRISM) have confirmed the association of sulfate hydrates with light-toned layered deposits [e.g., Bishop et al., 2008; Lichtenberg et al., 2008]. In some cases, these layered deposits are several hundred meters thick [Roach et al., 2008], and although water is a requirement for formation, the exact nature of the water (e.g., atmospheric, standing, transient) during formation, and hence the timing in relation to the formation of Valles Marineris, is a matter of ongoing debate [e.g., Chapman and Tanaka, 2001; Komatsu et al., 2004; Catling et al., 2006; Mangold et al., 2008; Okubo et al., 2008]. In situ evidence from rover observations also suggest the presence of hydrated magnesium sulfate minerals [Squyres et al., 2004], such as kieserite, epsomite, and meridianiite $\left(\mathrm{MgSO}_{4} \cdot 11 \mathrm{H}_{2} \mathrm{O}\right)$ [Peterson and Wang, 2006], which are capable of repeat hydration cycles under presentday martian conditions [Chou and Seal, 2007], although metastability and irreversible kinetic pathways might be important for some of the phase changes [e.g., Vaniman and Chipera, 2006; Chipera and Vaniman, 2007; Wang et al., 2009].

[4] Determining the location and role of water on Mars today, and its effects over geological time, requires a proper understanding of both the thermodynamic and the mechanical stability of sulfate hydrates under martian conditions. The mechanical properties of these hydrates are of importance because they may be involved in controlling the stability of slopes and canyon walls. Here we address the mechanical properties of magnesium sulfate hydrates by using well-validated experimental rock physics techniques. Specifically, we aim to determine the drained unconfined compressive strength (UCS or $\sigma_{\mathrm{c}}$ ), Young's modulus $(E)$, and Poisson's ratio $(\nu)$ of martian sulfate analogs as these are key parameters in governing the strength and deformability of similar deposits on Mars [e.g., Okubo, 2007]. The goal of this study is twofold: (1) to determine the mechanical properties of sulfate hydrates in general to better understand their mechanical stability on Mars and (2) to quantify any relationship between hydration state and strength to assess the role of water of hydration in the distribution and ongoing evolution of light-toned layered deposits. Ultimately, we hope to better understand the mechanical response of hydrated sulfate-bearing layers to changes in obliquity on Mars.

\section{Sample Preparation and Characterization}

[5] Synthetic specimens of the minerals kieserite (hereafter termed MS1), epsomite (MS7), and meridianiite (MS11), chosen as structural and physical property analogs for martian sulfate hydrates, were prepared and characterized as follows. The MS7 sample used was reagent-grade powder purchased from Sigma-Aldrich. The MS1 sample, also purchased from Sigma-Aldrich in the form of reagent- grade powder, was intended to be identical to the mineral kieserite, which has the chemical formula $\mathrm{MgSO}_{4} \cdot \mathrm{H}_{2} \mathrm{O}$; however, analysis of the material supplied indicated that it had a higher water content (see next paragraphs), corresponding approximately to $\mathrm{MgSO}_{4} \cdot 1.25 \mathrm{H}_{2} \mathrm{O}$ (MS1.25). When preparing the samples for the deformation experiments, both MS1.25 and MS7 were ground in a coffee grinder and sieved to a grain size of less than $200 \mu \mathrm{m}$ for consistency between samples and comparison with previous studies [e.g., de Meer and Spiers, 1995]. Following the method described by Fortes et al. [2008a], $\mathrm{MgSO}_{4} \cdot 11 \mathrm{H}_{2} \mathrm{O}$ was prepared from a stoichiometric aqueous solution (37.78 wt $\%$ $\mathrm{MgSO}_{4}$ in $\mathrm{H}_{2} \mathrm{O}$ ) at $\sim 100^{\circ} \mathrm{C}$; this liquid was decanted into a high-density polyethylene container and immersed in liquid nitrogen. The resulting solid plug of polycrystalline material was broken up into subcentimeter chunks with a hammer in UCL Earth Sciences' cold room facility (air temperature of $-15^{\circ} \mathrm{C}$ ) and, subsequently, was ground and sieved in a similar manner to the two lower hydrates. To ensure reproducible mechanical results, we prepared samples suitable for mechanical deformation with a length-to-diameter ratio of 3:1 (75 mm long by $25 \mathrm{~mm}$ diameter) [Mogi, 1966; Hawkes and Mellor, 1970] by packing these powders into a split die assembly and pressing to $\sim 150 \mathrm{MPa}$. Samples were precision-lathed before deformation to ensure flat- and parallel-loading faces.

[6] For each hydrate phase, we checked the purity of a representative sample using $\mathrm{X}$-ray diffraction analysis on a PANalytical XPert Pro powder diffractometer (Co $\mathrm{K} \alpha_{1}$ radiation). The MS7 powder was supplied as $99 \%$ pure and, after powdering, packing, and lathing, exhibited no discernible change in bulk composition. The MS1.25 sample was supplied as nominally $97 \%$ pure $\mathrm{MgSO}_{4} \cdot \mathrm{H}_{2} \mathrm{O}$. However, the bulk composition of this material seems to correspond to that of the poorly characterized hydrate of $\mathrm{MgSO}_{4}$, with a composition of $\mathrm{MgSO}_{4} \cdot 1.25 \mathrm{H}_{2} \mathrm{O}$; also, in material scraped from the surface of our prepared kieserite cylinder, we detected the onset of formation of higher hydrates. As shown in Figure 1a, the X-ray powder diffraction patterns of the surface scraping contains numerous sharp Bragg reflections, which, in both position and intensity, agree with the expected diffraction pattern of sanderite $\left(\mathrm{MgSO}_{4} \cdot 2 \mathrm{H}_{2} \mathrm{O}\right)$ [Ma et al., 2009]. The remaining observed Bragg reflections match well with those reported from the poorly known $\mathrm{MgSO}_{4} \cdot 1.25 \mathrm{H}_{2} \mathrm{O}$ phase, which has been previously referred to as "synthetic kieserite" [Emons et al., 1990]. On the basis of these X-ray diffraction data, it appears that no (or very little) kieserite [Aleksovska et al., 1998] is present. In particular, the single broad feature at $\sim 2 \theta=32^{\circ}$ in our $\mathrm{X}$-ray powder diffraction pattern cannot be explained by kieserite, but instead, this closely matches two close Bragg peaks in the 1.25 hydrate. Consequently, we checked the exact water content of the MS1 starting material as supplied by Sigma-Aldrich using a thermogravimetric method, similar to that of Emons et al. [1990]. We heated a small ( $\sim \mathrm{g})$ sample of the supplied MS1 to $400^{\circ} \mathrm{C}$ for 24 hours and measured a mass reduction of $16.9 \%$; the water contents of $\mathrm{MgSO}_{4} \cdot \mathrm{H}_{2} \mathrm{O}, \mathrm{MgSO}_{4} \cdot 1.25 \mathrm{H}_{2} \mathrm{O}$, and $\mathrm{MgSO}_{4} \cdot 2 \mathrm{H}_{2} \mathrm{O}$ are $13.0 \%, 15.8 \%$, and $23.0 \%$, respectively. Therefore, it is likely that our supplied MS1 contains a large proportion of $\mathrm{MgSO}_{4} \cdot 1.25 \mathrm{H}_{2} \mathrm{O}$, which, although having no significant effect on our results (see discussion on porosity below), does 

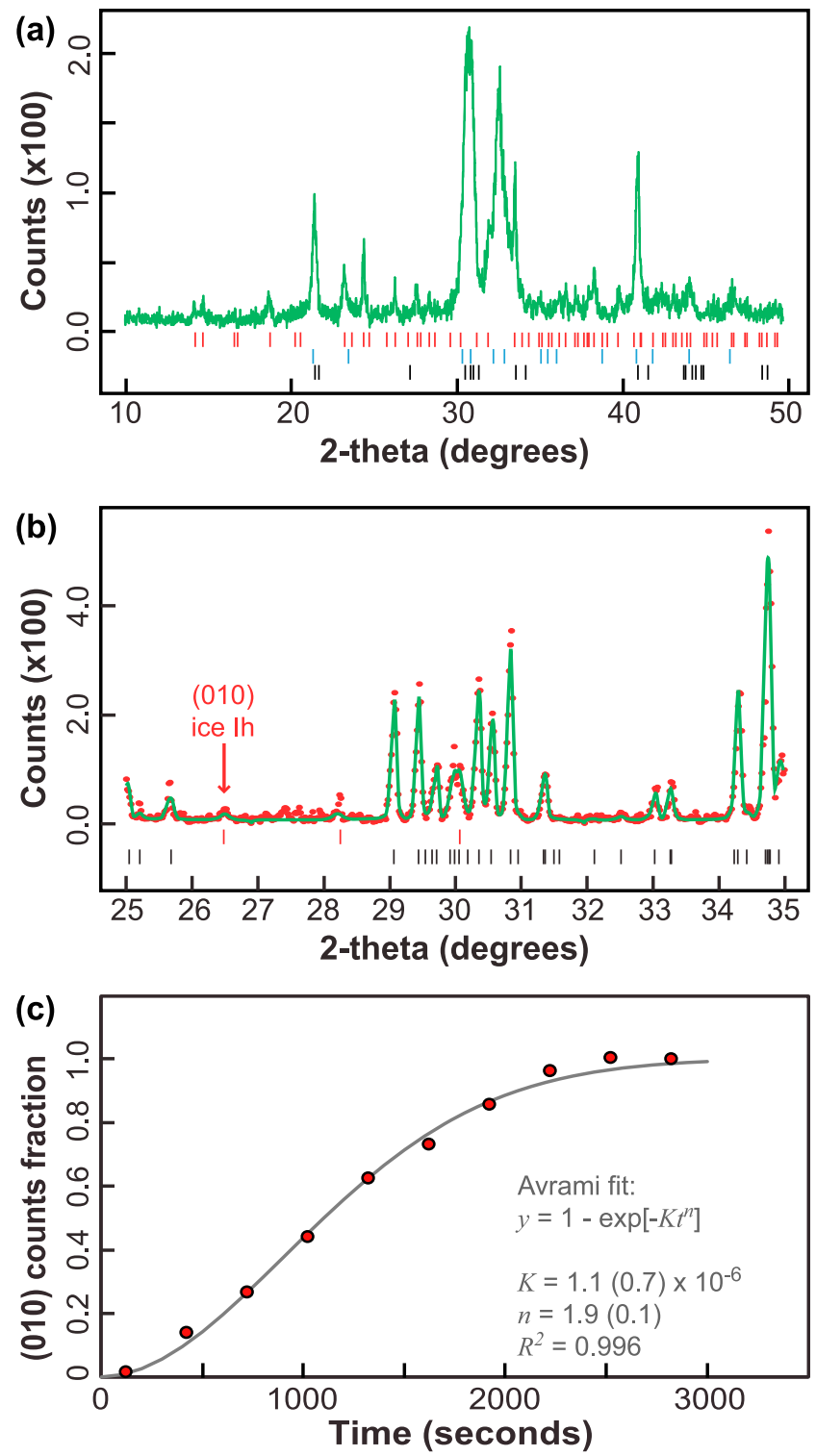

Figure 1. X-ray powder diffraction analysis of representative samples. (a) Diffraction pattern (Co $\mathrm{K} \alpha_{1}$ radiation) obtained from surface scrapings of a pressed kieserite sample. Expected Bragg reflections from kieserite $\left(\mathrm{MgSO}_{4}\right.$. $\mathrm{H}_{2} \mathrm{O}$ ) are indicated by the black (bottom) tic marks, synthetic kieserite $\left(\mathrm{MgSO}_{4} \cdot 1.25 \mathrm{H}_{2} \mathrm{O}\right)$ by the blue (middle) tic marks, and those from sanderite $\left(\mathrm{MgSO}_{4} \cdot 2 \mathrm{H}_{2} \mathrm{O}\right)$ by the red (top) tic marks. (b) $\mathrm{X}$-ray diffraction pattern of MS11 in the diagnostic range $2 \theta=25^{\circ}-35^{\circ}$ at time $t=1-$ $5 \mathrm{~min}$, with Rietveld refinement showing $1.5 \mathrm{wt} \%$ ice in the sample. Black (bottom) tic marks are MS11 peaks, and red (top) tic marks are ice Ih peaks. (c) Relative increase in the intensity of the (010) ice Ih peak (red points), with the fitted Avrami equation (solid gray line) showing that the MS11 sample was ice free at time $t=0$. The parameter fits to the Avrami equation are also given, with the standard errors given in brackets. mean that we prefer to use the term MS1.25 throughout this paper when referring to this sample.

[7] In the case of X-ray diffraction analysis of MS11, we constructed a small cold stage using a Peltier cooler and aluminum alloy radiator coupled to a sample stage enclosed in an X-ray transparent polyester film; this allowed us to maintain a sufficiently low temperature to prevent incongruent melting of MS1 1 at $2{ }^{\circ} \mathrm{C}$ and to limit the availability of atmospheric moisture that could condense on the specimen. The version of the cold stage used for this experiment was a prototype in which the sample was imperfectly sealed from the atmosphere in the laboratory; consequently, we found that a highly oriented film of water-ice grew rapidly on the exposed MS11 surface. We performed a series of rapid ( 4 min) scans over the angular range $=25^{\circ}-35^{\circ}$ that allowed us to observe the growth of the ice film and so determine the purity of the original sample (at time $t=0$ ). Figure $1 \mathrm{~b}$ shows the first diffraction pattern: very weak Bragg reflections from ice (red tic marks) are present. Rietveld refinement yields an ice abundance of $1.5 \mathrm{wt} \%$ after $4 \mathrm{~min}$, growing to $55 \mathrm{wt} \%$ after $50 \mathrm{~min}$. Extrapolating backward to time $t=0$ using the equation of Avrami [1939] (Figure 1c) shows that our quenched specimens are initially ice free. The value of the Avrami exponent, $n=1.9$ (Figure 1c) is indicative of platy (i.e., two-dimensional) interfacial growth on a substrate that is saturated in nucleation sites, for which we would expect $n \equiv 2$. Clearly, quenching of stoichiometric liquid in liquid nitrogen yields the equilibrium phase and does not result in disproportionation to a mixture of MS7 + ice.

[8] Measuring the porosity of our magnesium sulfate samples is nontrivial because most methods involve either the destruction of a sample or the use of a saturating (and, in this case, dissolving) fluid. Therefore, we sought to measure the porosity using nondestructive methods. The total porosity of each sample was determined using a relative density method by comparing the sample density, measured with digital calipers and mass balance, with that of the pure hydrate phase; the precision of our total porosity measurements is high (absolute maximum probable error $<2 \%$ for all samples). We also used two additional methods of measuring porosity on representative samples: (1) saturation in silicone oil and (2) gas pycnometry. By comparing the results from the three different analytical techniques, we can determine the proportion of isolated and connected pores.

[9] We measured the effective (connected) porosity of samples of MS1.25 and MS7 by vacuum-driven saturation in silicone oil at room temperature. We used silicone oil as the saturation medium rather than water because of the high solubility of magnesium sulfate hydrates in water. The dry mass of each sample was recorded before the sample was left to saturate for several hours in the silicone oil, immediately after which the wet mass was recorded. The relative mass increase allowed the effective porosity to be determined. Our saturated samples of MS1.25 and MS7, which were not used in deformation tests, have total porosities of $49.3 \%$ and $6.4 \%$, respectively, compared with effective porosities of $19.4 \%$ and $2.2 \%$, respectively, yielding totalto-effective porosity ratios of 2.5 and 2.9 , respectively. These ratios are toward the upper range found in natural evaporates [e.g., Bell, 2000], indicating that our sample 
(a)

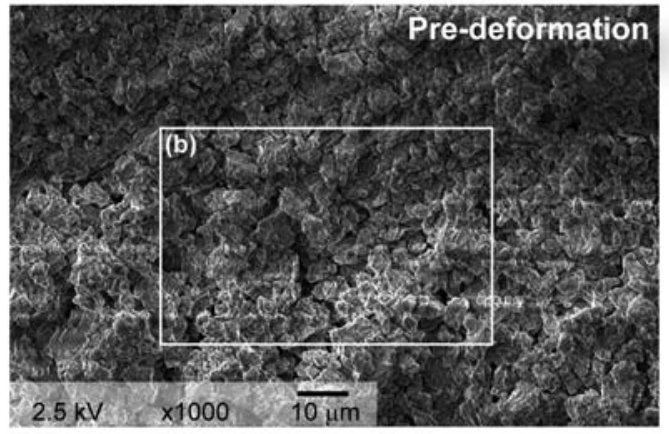

(c)

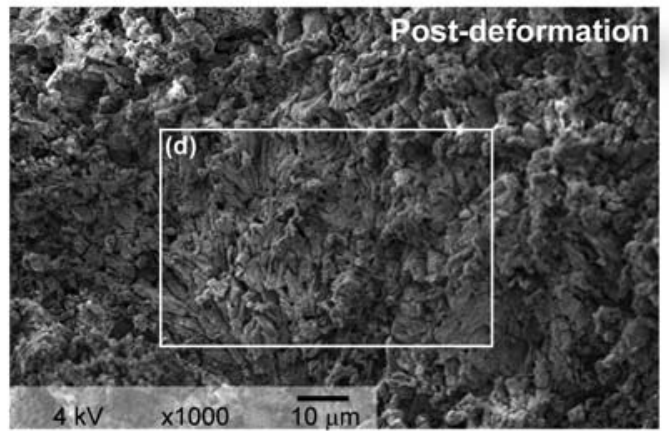

(b)

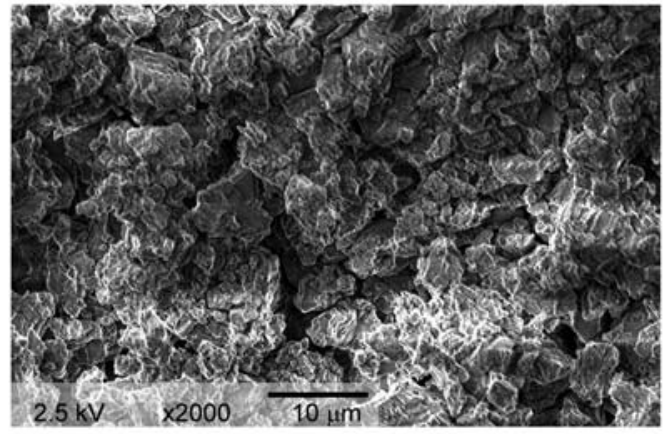

(d)

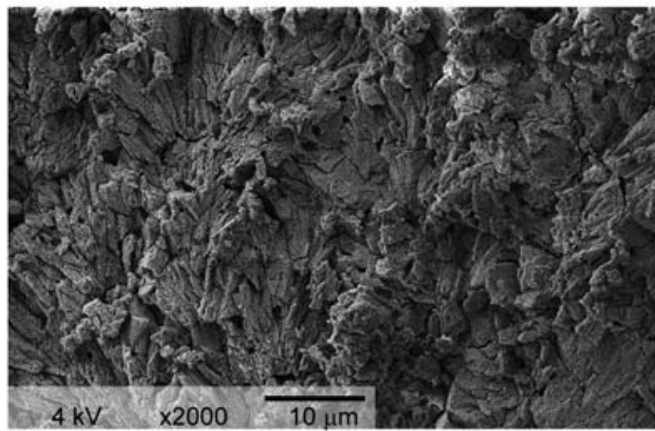

Figure 2. SEM analysis of representative MS1.25 samples. (a) Predeformation SEM image of a sample not used in the deformation tests showing the individual grains and widespread pores. The bright horizontal lines are SEM charging artifacts due to rapid gold coating to avoid vacuum dehydration. The sample was cut through and lathed along its short axis; that is, this image reveals mostly radial pores. (b) SEM image of the same sample as in Figure 2a, although at a higher magnification. The fine grain size and, even after sample compaction and lathing, high porosity of this sample are evident at this resolution. The low connected porosity in this sample has resulted in few "deep" pore spaces. (c) Postdeformation SEM image of a fracture surface in the MS1.25 sample used in MS1.25 run 5 showing a reduction in pore size and density and some possible deformation-related grain orientation. (d) SEM image of the same sample as in Figure 2c, although at a higher magnification. The reduction in porosity after deformation is evident from the lack of deep connected pores.

preparation method is efficient at isolating pores but not necessarily at closing them.

[10] This difference in total and effective porosity is not surprising because we would expect the effective porosity to be less than the total porosity because saturation penetrates only those pores connected to the surface and does not reflect the porosity of the bulk sample. There is a possibility that the low connected porosity is the result of using silicone oil rather than water. Using the equation of Washburn [1921], we estimate that, although the minimum pore size that silicone oil can penetrate is approximately four times the diameter of the pores accessible to water, it is still in the submicrometer range. This minimum pore size can be compared with pores visible in a scanning electron microscope (SEM) analysis of another representative MS1.25 sample (Figures 2a and 2b). At this resolution, individual grains and pores are visible and do not appear to have any preferred orientation. Individual pores less than $\sim 10 \mathrm{~m}$ are evident as gaps between grains and, in a few cases, join together to form connected pore networks. From these SEM images on an undeformed sample, it is not possible to quantitatively determine the exact porosity, although it is evident that there appears to be no preferred pore orientation.
[11] We also measured the total porosity of the same MS1.25 sample used in the SEM analysis using gas pycnometry. We used a Micromeritics AccuPyc 1330 helium pycnometer on a sample lathed down to an apparent volume of $0.862 \mathrm{~cm}^{3}$ (maximum standard error $\sim 15 \%$ ). We measured the mean true volume and specific gravity of the sample to be $0.4155 \mathrm{~cm}^{3}$ and 2.5782 , respectively, from 10 individual analyses in the pycnometer, giving one SD precision errors of $<0.4 \%$ in both cases. This yielded a porosity value from pycnometry $(51.8 \% \pm 0.3 \%)$ comparable with that measured through density analysis (mean porosity $=49.0 \% \pm 0.2 \%$ ). Because helium is highly penetrating, we would expect the results from helium pycnometry to be in good agreement with the total porosity determined from the relative density, and this is indeed the case.

[12] It is also necessary to determine the effects on our porosity measurements of our supplied MS1 most likely being dominated by MS1.25. Because the structure of $\mathrm{MgSO}_{4} \cdot 1.25 \mathrm{H}_{2} \mathrm{O}$ is yet to be solved, the exact density of this phase is also unknown. However, if the density of the 1.25 hydrate lies proportionally between that of the monohydrate $\left(2570 \mathrm{~kg} \mathrm{~m}^{-3}\right)$ and the dihydrate $\left(2370 \mathrm{~kg} \mathrm{~m}^{-3}\right)$, we can estimate the density of "synthetic kieserite" as $2520 \mathrm{~kg} \mathrm{~m}^{-3}$. This change in pure phase density would result in a decrease 


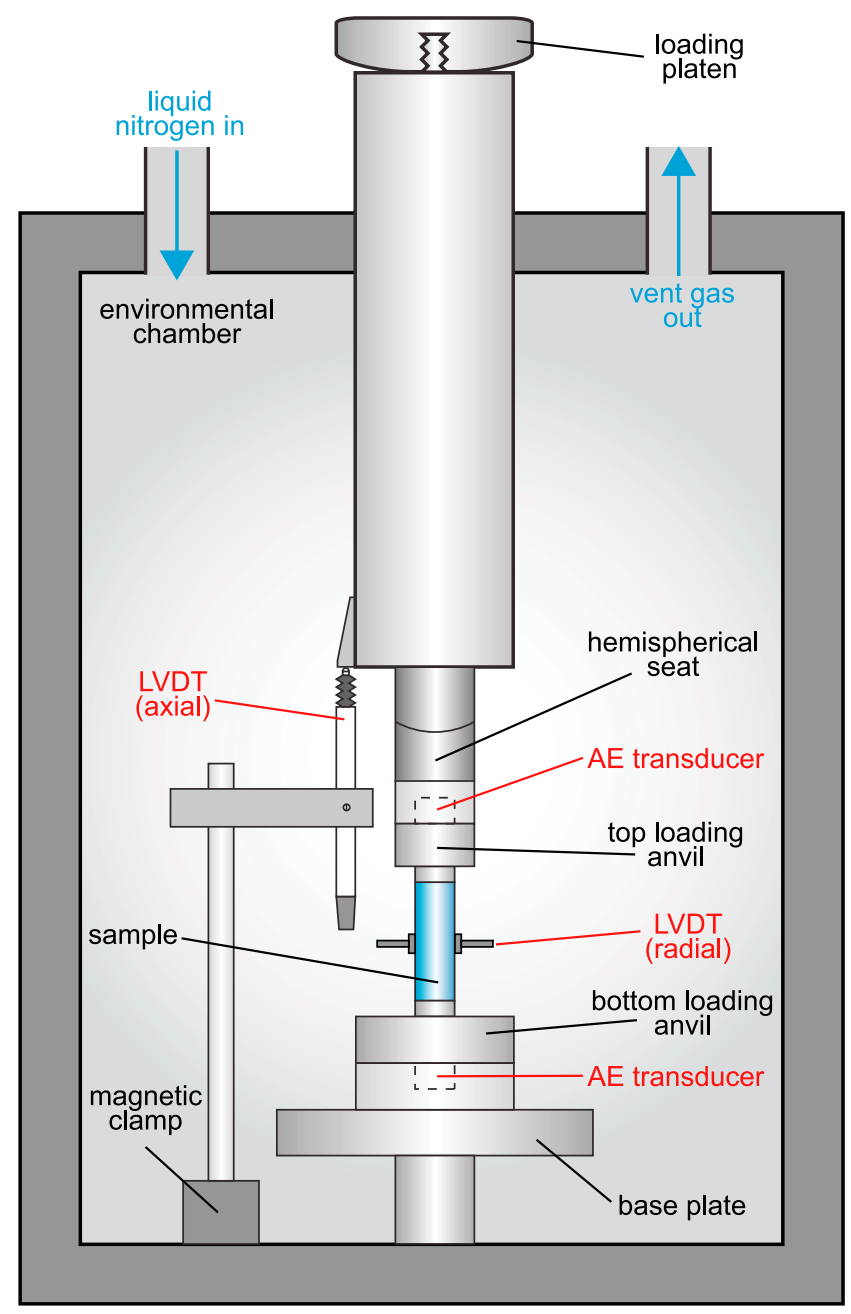

Figure 3. Schematic diagram of the deformation apparatus used in this study highlighting the load string (not to scale). The hemispherical seat ensures loading is normal to the sample face. The loading platen is fitted to a servo-controlled $200 \mathrm{kN}$ load frame. Samples are $25 \mathrm{~mm}$ in diameter and $75 \mathrm{~mm}$ long.

in our calculated porosities of $1 \%$ for all our MS1 samples. Because the density of MS1.25 above is an estimate because of its structure being unsolved, we use the known density of $\mathrm{MgSO}_{4} \cdot \mathrm{H}_{2} \mathrm{O}$ in calculating the porosity of MS1.25 throughout. Therefore, we are confident that our relative density porosity measurements for representative samples compare well with those from alternative methods and that our porosity values for all samples used in our deformation experiments are accurate.

\section{Experimental Procedure}

[13] We applied well-validated experimental rock physics techniques, used in the study of terrestrial volcanic samples and systems [e.g., Bredthauer, 1957; Murrell and Chakravarty, 1973; Rohde and Feng, 1990; Schultz, 1993, 1995; Rocchi et al., 2002; Heap et al., 2009], to our synthetic magnesium sulfate hydrates. We used a servo-controlled $200 \mathrm{kN}$ uniaxial load frame (Figure 3), with an environmental chamber capable of temperatures of between $-150^{\circ} \mathrm{C}$ and $350^{\circ} \mathrm{C}$, to conduct unconfined compression tests. Using the signal from an external linear voltage displacement transducer, we deformed samples at a constant axial strain rate while monitoring the resultant axial and radial strains. We also recorded acoustic emission (AE) energy, a proxy for crack damage, over the range $0.1-1 \mathrm{MHz}$ using a MISTRAS-2001 system with broadband piezoelectric transducers located inside the top and bottom loading anvils [Cox and Meredith, 1993]. Each sample was sealed from the environment during deformation by a thin $(\sim 10 \mu \mathrm{m})$ layer of low-density polyethylene, which prevented possible humidity-related phase changes without affecting sample strength or radial strain measurements.

[14] We carried out two main types of constant strain rate tests: (1) compression-to-failure to determine UCS $\left(\sigma_{\mathrm{c}}\right)$ and static elastic moduli, Young's modulus $(E)$, and Poisson's ratio $(\nu)$, during a single loading cycle, and (2) cyclic stressing tests with incrementally increasing load to determine the evolution of elastic moduli with increasing crack damage. Strictly, our calculated values are the static elastic moduli, as opposed to the dynamic elastic moduli determined from elastic wave velocities. In both types of compression tests, our values of UCS are the maximum stresses recorded before sample failure, whether in a brittle or in a ductile manner. We obtained static elastic moduli during the quasielastic (linear) portion of a load cycle. The Young's modulus, or tangent modulus [e.g., International Society of Rock Mechanics, 1978; Jaeger et al., 2007], was calculated using the local gradient of a third-order polynomial fitted to the stress-strain curve [Faulkner et al., 2006; Heap and Faulkner, 2008], and this is given by

$$
E=\partial \sigma / \partial \varepsilon_{\text {axial }}
$$

with a similar approach used to determine Poisson's ratio given by

$$
\nu=-\partial \varepsilon_{\text {radial }} / \partial \varepsilon_{\text {axial }}
$$

where $\sigma$ is the applied longitudinal stress and $\varepsilon_{\text {axial }}$ and $\varepsilon_{\text {radial }}$ are the axial and radial strains, respectively. In cyclic stressing tests, we repeatedly loaded and unloaded the sample at a constant strain rate, increasing the maximum load at each cycle while always unloading to a similar minimum stress in each test. These tests allowed us to quantify the evolution of static elastic moduli with pore collapse and/or increasing crack damage.

\section{Results}

[15] We have carried out 35 uniaxial compression tests, with 12 on MS1.25, 11 on MS7, and 12 on MS11. We used controlling strain rates of between $1.2 \times 10^{-4}$ and $6.8 \times 10^{-7} \mathrm{~s}^{-1}$ and environmental temperatures between 223 and $323 \mathrm{~K}$. Of these tests, 32 were single compressionto-failure tests and 3 were cyclic-stressing tests. All results are given in Table 1, and described below in more detail.

\subsection{Compression-to-Failure Tests}

[16] Representative results from single-loading failure tests, showing loading path and AE energy, are shown in Figure 4. In these examples, samples of MS1.25, MS7, and MS11 failed at $6.4,9.4$, and $75.0 \mathrm{MPa}$ at temperatures of 
Table 1. Results of All Uniaxial Compression Tests

\begin{tabular}{|c|c|c|c|c|c|c|c|c|}
\hline Material & Run & Type & $\begin{array}{c}\text { Porosity } \\
\text { Total, } \phi \\
(\%)\end{array}$ & $\begin{array}{c}\text { Temperature, } \\
T(\mathrm{~K})\end{array}$ & $\begin{array}{l}\text { Strain } \\
\text { Rate, } \\
\varepsilon\left(\mathrm{s}^{-1}\right)\end{array}$ & $\begin{array}{c}\text { UCS, } \\
\sigma_{\mathrm{c}} \\
(\mathrm{MPa})\end{array}$ & $\begin{array}{c}\text { Young's } \\
\text { Modulus, E } \\
\text { (GPa), } \\
\text { Mean (SD) }\end{array}$ & $\begin{array}{c}\text { Poisson's } \\
\text { Ratio } \nu, \\
\text { Mean } \\
\text { (SD) }\end{array}$ \\
\hline MS1.25 & 1 & Single & 49.5 & 300 & $1.98 \times 10^{-6}$ & 4.66 & $0.52(0.05)$ & $0.18(0.15)$ \\
\hline MS1.25 & 2 & Single & 49.1 & 300 & $1.74 \times 10^{-6}$ & 4.37 & $0.48(0.09)$ & \\
\hline MS1.25 & 3 & Single & 45.8 & 300 & $1.75 \times 10^{-6}$ & 8.39 & $1.08(0.07)$ & \\
\hline MS1.25 & 4 & Single & 48.4 & 300 & $3.55 \times 10^{-6}$ & 4.71 & $0.48(0.05)$ & \\
\hline MS1.25 & 5 & Single & 45.8 & 300 & $1.73 \times 10^{-6}$ & 9.53 & $1.02(0.04)$ & \\
\hline MS1.25 & 6 & Single & 45.4 & 300 & $1.79 \times 10^{-6}$ & 7.05 & $0.84(0.08)$ & \\
\hline MS1.25 & 7 & Single & 48.9 & 248 & $3.64 \times 10^{-6}$ & 5.13 & $0.57(0.06)$ & \\
\hline MS1.25 & 8 & Single & 48.2 & 248 & $3.52 \times 10^{-6}$ & 4.42 & $0.56(0.05)$ & \\
\hline MS1.25 & 9 & Cyclic & 49.2 & 300 & $3.55 \times 10^{-6}$ & 2.91 & $0.43(0.17)$ & \\
\hline MS1.25 & 10 & Single & 48.7 & 248 & $3.42 \times 10^{-6}$ & 6.43 & $0.79(0.04)$ & \\
\hline MS1.25 & 11 & Single & 45.4 & 323 & $2.19 \times 10^{-5}$ & 9.98 & $1.54(0.06)$ & $0.29(0.18)$ \\
\hline MS1.25 & 12 & Single & 48.7 & 233 & $3.42 \times 10^{-6}$ & 4.34 & $0.58(0.04)$ & \\
\hline MS7 & 1 & Single & - & 300 & $6.75 \times 10^{-7}$ & 6.25 & $0.52(0.06)$ & \\
\hline MS7 & 2 & Single & - & 300 & $1.27 \times 10^{-6}$ & 13.63 & $2.21(0.49)$ & $0.14(0.01)$ \\
\hline MS7 & 3 & Single & 9.7 & 300 & $1.86 \times 10^{-4}$ & 12.57 & $2.59(0.36)$ & $0.14(0.03)$ \\
\hline MS7 & 4 & Single & 9.4 & 300 & $2.92 \times 10^{-4}$ & 17.98 & $3.16(0.22)$ & $0.08(0.03)$ \\
\hline MS7 & 5 & Single & 10.8 & 300 & $5.96 \times 10^{-4}$ & 6.92 & $2.84(0.26)$ & \\
\hline MS7 & 6 & Single & 10.2 & 300 & $1.21 \times 10^{-4}$ & 21.17 & $3.62(0.21)$ & $0.10(0.03)$ \\
\hline MS7 & 7 & Cyclic & 10.3 & 300 & $1.67 \times 10^{-6}$ & 25.42 & $3.98(0.13)$ & \\
\hline MS7 & 8 & Cyclic & 9.5 & 300 & $1.66 \times 10^{-6}$ & 20.32 & $5.92(0.66)$ & $0.15(0.11)$ \\
\hline MS7 & 9 & Single & 11.7 & 248 & $9.15 \times 10^{-6}$ & 18.54 & $5.48(0.30)$ & \\
\hline MS7 & 10 & Single & 15.0 & 248 & $5.56 \times 10^{-6}$ & 9.34 & $3.30(0.27)$ & \\
\hline MS7 & 11 & Single & 13.0 & 248 & $3.58 \times 10^{-6}$ & 9.52 & $2.27(0.41)$ & \\
\hline MS11 & 1 & Single & 4.1 & 248 & $3.66 \times 10^{-6}$ & 29.59 & $4.18(0.25)$ & \\
\hline MS11 & 2 & Single & 2.0 & 261 & $1.90 \times 10^{-5}$ & 13.46 & $2.25(0.37)$ & \\
\hline MS11 & 3 & Single & 3.0 & 261 & $1.88 \times 10^{-5}$ & 16.91 & $2.34(0.10)$ & \\
\hline MS11 & 4 & Single & 1.8 & 248 & $9.49 \times 10^{-6}$ & 28.20 & $4.03(0.56)$ & \\
\hline MS11 & 5 & Single & 2.8 & 248 & $5.78 \times 10^{-6}$ & 34.33 & $4.90(0.36)$ & \\
\hline MS11 & 6 & Single & 1.9 & 223 & $9.92 \times 10^{-6}$ & 75.04 & $10.45(0.98)$ & $0.06(0.01)$ \\
\hline MS11 & 7 & Single & 3.4 & 223 & $5.69 \times 10^{-6}$ & 24.76 & $4.23(0.20)$ & \\
\hline MS11 & 8 & Single & 3.3 & 223 & $9.09 \times 10^{-6}$ & 24.97 & $8.13(0.23)$ & \\
\hline MS11 & 9 & Single & 3.7 & 223 & $6.26 \times 10^{-6}$ & 33.71 & $8.70(0.77)$ & \\
\hline MS11 & 10 & Single & 2.7 & 223 & $4.11 \times 10^{-6}$ & 33.22 & $7.47(0.34)$ & \\
\hline MS11 & 11 & Single & 2.6 & 223 & $2.22 \times 10^{-6}$ & 25.15 & $6.58(1.33)$ & \\
\hline MS11 & 12 & Single & 2.9 & 233 & $6.83 \times 10^{-6}$ & 27.85 & $7.86(0.68)$ & \\
\hline
\end{tabular}

248, 248, and $223 \mathrm{~K}$, respectively. Samples demonstrating higher UCS also yielded a greater AE energy. Although we do not specifically address postfailure behavior in this study, we do note that of the 32 single-compression-to-failure tests, 28 resulted in failure in a gross brittle manner, with a sudden marked decrease in stress and usually significant, if not complete, axial fracturing on failure. Four tests on MS11 (runs 1,2,3, and 5) resulted in ductile failure, with little or no axial fracturing, and a gradual loss in strength after peak stress had been achieved (Figure 5). As a system, our magnesium sulfate hydrates have UCS values between 4.3 and $75.0 \mathrm{MPa}$ across the temperature range studied. Individually, MS1.25, MS7, and MS11 have mean UCS values of $6.3 \pm 0.7 \mathrm{MPa}$ (range $=4.3-10.0 \mathrm{MPa}), 12.9 \pm 1.8 \mathrm{MPa}$ $($ range $=6.3-21.2 \mathrm{MPa})$, and $30.1 \pm 4.5 \mathrm{MPa}($ range $=13.5$ 75.0 MPa), respectively. Test temperature seems to exert little influence on the UCS and elastic moduli of our samples, except for tests on MS11 close to its incongruent melting temperature, and hence undergoing ductile deformation, which failed at lower stress. Our MS1.25 samples showed sufficient range in porosity to demonstrate that porosity is the dominant parameter in determining the mechanical properties of our samples (Figure 6), the justification of which we discuss in section 5.1, and allows us to consider the magnesium sulfate system as a whole.
[17] Our samples of MS1.25, MS7, and MS11 have mean porosity values of $47.8 \% \pm 0.5 \%, 11.1 \% \pm 0.6 \%$, and $2.9 \%$ $\pm 0.2 \%$, respectively, showing a negative trend with UCS. We describe this trend using the theoretical approach of Phani and Niyogi [1987] for describing Young's modulus as a function of porosity in porous brittle solids, where the UCS is given by

$$
\sigma_{c}=\sigma_{0}\left(1-\phi / \phi_{c_{3}}\right)^{f_{3}}
$$

where $\sigma_{0}$ is the UCS at zero porosity, $\phi$ is the porosity, $\phi_{\mathrm{c}_{3}}$ is the critical porosity at which UCS is zero, and $f_{3}$ is an exponential factor. Here we assume that UCS will be 0 when porosity is equal to 1 , when a sample would effectively contain no solid components. The values of the parameters obtained by fitting the data shown in Figure 7a to equation (3) are given in Table 2, the fit is shown in Figure 7a by a solid line (coefficient of determination, $R^{2}=0.54$ ). Reducing $\phi_{\mathrm{c}_{3}}$ to 0.5 reduces $f_{3}$ by roughly a similar amount $(\sim 41 \%)$, but has little effect on $\sigma_{0}$ and $R^{2}$.

[18] The elastic moduli of magnesium sulfate hydrates show a similar porosity-dominated trend to that of their UCS. The Young's modulus determined from single loading tests ranged between 0.5 and $10.5 \mathrm{GPa}$. Different phases show significant variation in Young's modulus, with 

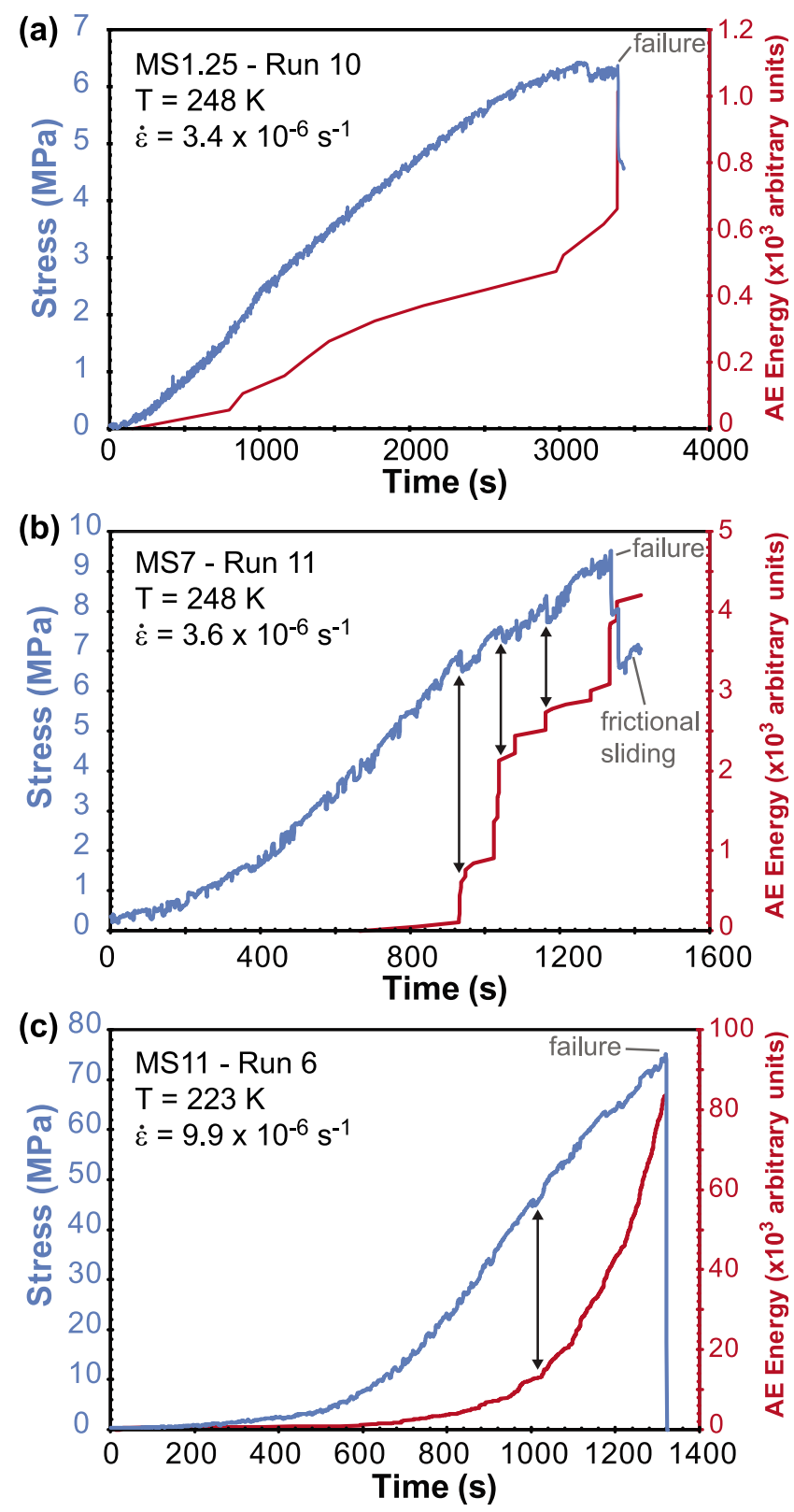

Figure 4. Representative results from single compressionto-failure tests for (a) MS1.25, (b) MS7, and (c) MS11. In each case, the run number, temperature, and strain rate are given in addition to the stress (solid blue line) and $\mathrm{AE}$ (solid red line) as a function of time. Jumps in cumulative energy correspond with stress drops (black arrows), indicating that cracking of the sample is associated with release of acoustic energy [e.g., Tuffen et al., 2008]. The UCS values for these three samples of (a) MS1.25, (b) MS7, and (c) MS11 are 6.4, 9.5, and 75.0 $\mathrm{MPa}$, respectively.

MS1.25, MS7, and MS11 having mean Young's modulus values of $0.8 \pm 0.1 \mathrm{GPa}$ (range $=0.5-1.5 \mathrm{GPa}), 2.9 \pm 0.4 \mathrm{GPa}$ $($ range $=0.5-5.5 \mathrm{GPa})$, and $5.9 \pm 0.8 \mathrm{GPa}($ range $=2.3-$ $10.5 \mathrm{GPa}$ ). The Young's modulus of the samples again showed a negative trend with increasing porosity (Figure 7b), which we describe using the theoretical approach of Phani and Niyogi [1987], in which the Young's modulus is given by

$$
E=E_{0}\left(1-\phi / \phi_{c_{4}}\right)^{f_{4}}
$$

where $E_{0}$ is the Young's modulus at zero porosity, $\phi_{c_{4}}$ is the critical porosity at which Young's modulus is 0 , and $f_{4}$ is an exponential factor. We assume that Young's modulus will be zero when there are no solid components in the sample, effectively setting the critical porosity to one. The values of the parameters obtained by fitting the data shown in Figure $7 \mathrm{~b}$ to equation (4) are given in Table 3; they produce the best fit plot $\left(R^{2}=0.63\right)$ shown by the solid line in Figure $7 \mathrm{~b}$. Reducing $\phi_{c_{4}}$ to 0.5 reduces $f_{4}$ by roughly a similar amount $(\sim 43 \%)$, but this has little effect on $E_{0}$ and $R^{2}$.

[19] Determining Poisson's ratio in our tests proved problematic; movement of the radial linear voltage displacement transducer owing to either air movement from the environmental chamber fan or ice buildup during long duration cold runs meant that the Poisson's ratio could only be determined in seven of our compression-to-failure tests. Of these seven successful tests, two were on MS1.25, four on MS7, and one on MS11. The mean Poisson's ratio in these tests ranged from 0.06 to 0.24 , with the greatest range observed for MS1.25 samples, which had the highest porosities. During each test, the instantaneous value of Poisson's ratio increased with stress, indicating crack damage and/or or pore closure. Porosity is the major factor in determining the Poisson's ratio of a sample, which showed an increasing trend with increasing porosity (Figure 7c), which we describe using two different methods. First, we adopt the approach of Phani and Sanyal [2005] and assume that the pores in the samples are spherical so that Poisson's ratio can be given by

$$
\nu=0.5-\frac{3\left(1-2 \nu_{0}\right)\left(1-\phi^{2}\right)}{6\left[\left(a_{5} \phi+b_{5}\right) K_{p, 1}+\left(c_{5} \phi+d_{5}\right) K_{p, 2}\right]}
$$

where $\nu$ is the Poisson's ratio at zero porosity, $a_{5}, b_{5}, c_{5}, d_{5}$, and $K_{\mathrm{p}, 1}$ and $K_{\mathrm{p}, 2}$ are polynomial parameters related to

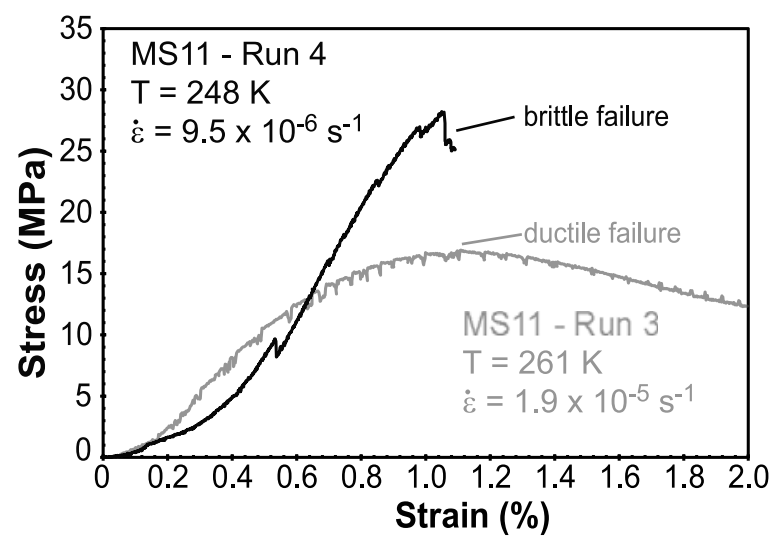

Figure 5. Brittle versus ductile failure mechanisms in MS11. Brittle failure in MS11 run 4 (solid black line) at $T=248 \mathrm{~K}$ is evident from the sudden loss of strength after peak stress at 28.2 MPa. Ductile failure in MS11 run 3 (solid gray line) at $T=261 \mathrm{~K}$ can still accommodate significant amounts of strain after failure at $16.9 \mathrm{MPa}$. 

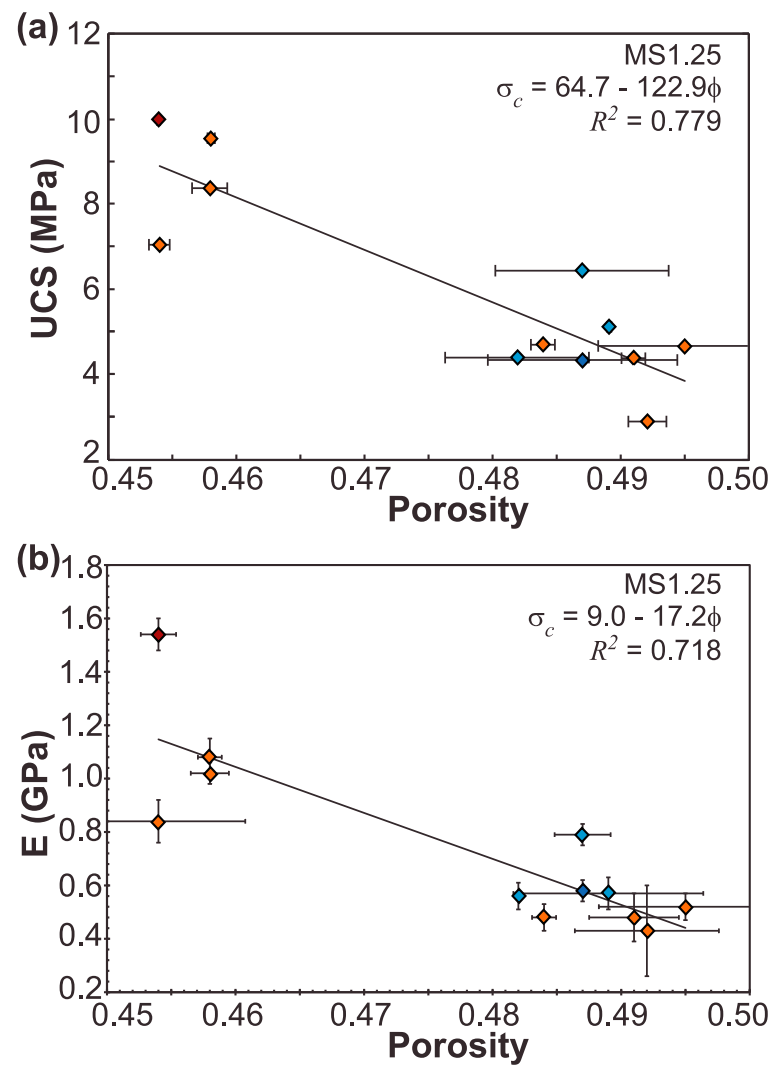

Temperature (K)

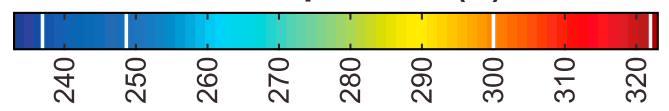

Figure 6. Mechanical properties of our MS1.25 samples as a function of porosity, which allows us to separate the effect of composition from the sample porosity. (a) UCS and (b) Young's modulus of all our tests on MS1.25 as a function of sample porosity demonstrating that an increase in porosity causes a decrease in overall strength. The fill colors represent the test temperatures as given in the scale bar. The white lines on the temperature scale represent the test temperatures of 233, 248, 300, and $323 \mathrm{~K}$. Porosity error bars are the maximum probable error, and vertical error bars are one SD for each experiment.

Young's modulus. The values of the parameters obtained from fitting equation (5) are given in Table 4; they produce the best fit plot $\left(R^{2}=0.76\right)$ shown by the broken line in Figure 7c. Second, for simplicity, we also fit an exponential curve for comparison with the theoretical fit, where Poisson's ratio is given by

$$
\nu=0.5-a_{6} \exp \left(b_{6} \phi\right)
$$

where the values of the fitted parameters $a_{6}$ and $b_{6}$ are given in Table 4 and used to produce the best fit plot $\left(R^{2}=0.77\right)$ shown by the solid line in Figure 7c.

\subsection{Cyclic-Stressing Tests}

[20] Representative results from a single cyclic-stressing test are shown in Figure 8. In this test, the MS7 sample was loaded and unloaded at a constant strain rate of $1.7 \times 10^{-6} \mathrm{~s}^{-1}$, at a temperature of $300 \mathrm{~K}$, yielding a UCS of $20.3 \mathrm{MPa}$ (Figure 8a). This single experiment lasted for more than 7 hours and, at the given strain rate, enabled the sample to undergo eight complete cycles, failing during the loading portion of the ninth cycle. Figure $8 \mathrm{~b}$ shows the corresponding stress-strain curve for this test and highlights the variation in the stress-strain response of the sample between loading cycles. To aid comparison between samples, all three cyclic-stressing tests were carried out under similar conditions, with a temperature of $300 \mathrm{~K}$, and strain rates between $1.7 \times 10^{-6}$ and $3.6 \times 10^{-6} \mathrm{~s}^{-1}$. The measured values of static elastic moduli in our cyclic tests are also controlled by sample porosity and show significant evolution throughout testing (Figure 9). In each test, the mean value of $E$, measured over the quasielastic region of each cycle, increases with increasing cycle number (Figure 9a). In the one cyclic test in which we were able to confidently determine the Poisson's ratio, MS7 run 8 (Figure 9b), increasing the number of stress cycles increased the Poisson's ratio from 0.02 to 0.35 , indicating significant microcrack damage during inelastic deformation.

\section{Discussion}

\subsection{Interpreting the Experimental Results}

[21] To apply the experimental results to similar deposits on Mars, it is necessary to first recognize any possible limitations of the experimental procedure and to properly understand the processes occurring during deformation testing. The porosity of our samples is inherited from the sample preparation methods and is similar to those used in other studies of synthetic sulfate hydrate samples produced by packing; for example, de Meer and Spiers [1995] produced synthetic samples of gypsum for hydrostatic compression testing by compacting dry powders of grain size between 37 and $125 \mu \mathrm{m}$, resulting in porosities of $45 \% \pm 3 \%$. The process of compaction of dry powders can be split into four main stages: (1) first granular reorganization, (2) fragmentation, (3) second granular reorganization, and (4) plastic deformation and intermolecular bonding [Lamy et al., 2005]. The porosity variation between the different hydrate phases investigated in this study is most likely the result of different amounts of grain crushing during the fragmentation stage of sample preparation and, therefore, suggests some hydration state-strength relationship. All powders were sieved to a similar grain size and so likely underwent similar amounts of initial granular reorganization on compaction.

[22] The presence of non-cation-coordinated water molecules, as found in the higher hydrates, likely reduces the bulk strength of sulfate hydrates, resulting in increased grain crushing during compaction, and hence a lower porosity, with increasing hydration state. In essence, the strongest individual grains produce the weakest samples through compaction. This process helps to explain our apparent paradoxical finding that the lowest hydrate in our study, MS1.25, was the weakest and justifies our interpretation that porosity is the governing factor in determining the bulk sample strength. Thus, although our tests have failed to quantify a direct relationship between hydration state and mechanical properties, the high correlation between com- 
position and porosity is probably indicative of hydrationcontrolled strength. To a certain extent, porosity can be a proxy for geological evolution, and any large near-surface sulfate hydrate deposit on Mars, regardless of formation method, is unlikely to be completely pore free. Therefore, sulfate hydrate deposits on Mars will likely have a strength that is governed by the bulk porosity rather than the strength of the pure solid phase. Terrestrial sulfate hydrate deposits, such as gypsum, have porosities typically in the range of between 1\% and 20\% [Papadopoulos et al., 1994; Olgaard et al., 1995; Hoxha et al., 2006], and we would expect a similar range to be of most interest for all but the most weakly consolidated martian deposits.

[23] Our samples demonstrated failure mechanisms typical of uniaxial compression tests on terrestrial rocks and ice.
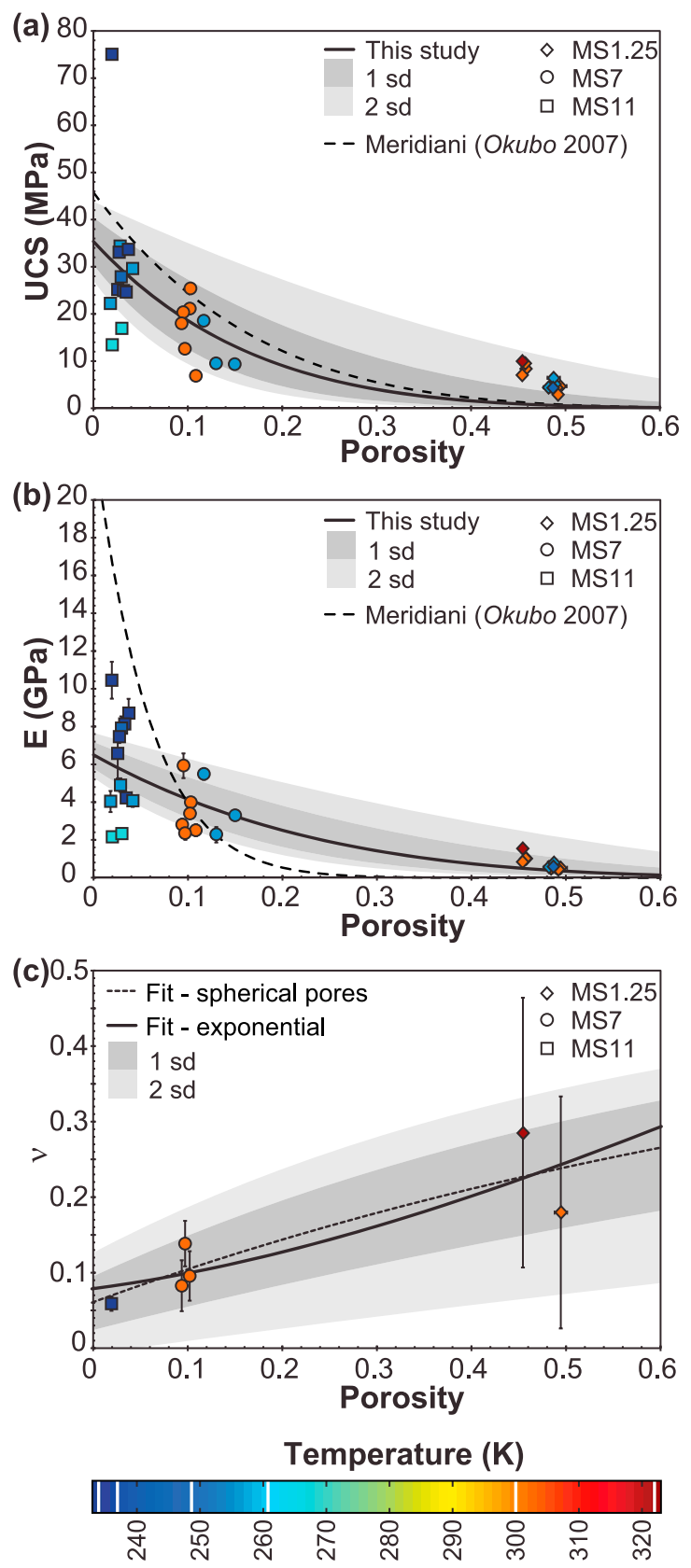

Mode I axial fracturing [e.g., Paterson and Wong, 2005] was evident in most samples after failure. Because our sample preparation and experimental method minimized boundary effects at the loading platen-sample interface, axial fracturing is most likely indicative of crack formation and/or opening parallel to the applied stress [e.g., Renshaw and Schulson, 2001; Schulson, 2001; Wachter et al., 2009]. The mechanical properties of our samples can be compared with those of terrestrial salts in uniaxial compression studies, where porosity is explicitly given. In a recent study, the anhydrous salts halite $(\mathrm{NaCl})$ and anhydrite $\left(\mathrm{CaSO}_{4}\right)$ were found to have zero-porosity mean UCS values of 18.7 and 23.9 $\mathrm{MPa}$, respectively [Liang et al., 2007], compared with our predicted zero-porosity UCS of the magnesium sulfate system of $35.4 \mathrm{MPa}$. The relative weakness of the natural salt samples is most likely the result of compositional interbedding between halite and anhydrite [Liang et al., 2007]. The anhydrous sulfates glauberite $\left(\mathrm{Na}_{2} \mathrm{Ca}\left(\mathrm{SO}_{4}\right)_{2}\right)$ and thenardite $\left(\mathrm{Na}_{2} \mathrm{SO}_{4}\right)$ have zero-porosity UCS values of 49 and $20 \mathrm{MPa}$, respectively, similar to this study [Liang and Zhao, 2004].

[24] The mechanical properties of our samples can also be compared with those estimated for possibly similar deposits on Mars. The most relevant comparative study determined the porosity-strength relationship for light-toned layered deposits near the Mars Exploration Rover Opportunity landing site in Meridiani Planum [Okubo, 2007]. In that study, apparent porosity was measured from Microscopic Imager (MI) observations of rock surfaces ground by the Rock Abrasion Tool (RAT) and related to strength by using the UCS of a terrestrial shale analog, measured in previous experimental studies [Lashkaripour and Dusseault, 1993; Horsund, 2001; Chang et al., 2006]. Figure 7 shows curves for UCS and Young's modulus as a function of porosity, which are fitted to the combined data of Okubo [2007]. Shale has previously been shown to be a good mechanical analog for martian layered deposits, both through the "grindability" of specific RAT targets in Meridiani Planum [Arvidson et al., 2004] and slope-stability studies in Valles Marineris [Schultz, 2002], and to a certain extent, our study validates this assumption. The porosity-dominated strength properties of our magnesium sulfates are also similar to those determined for a nonwelded tuff from Calico Hills,

Figure 7. Mechanical properties of the magnesium sulfate system as a function of porosity. In each case, the (a) UCS, (b) Young's modulus, and (c) Poisson's ratio are plotted as a function of porosity for the experimental results in this study. MS1.25, MS7, and MS11 are represented by diamonds, circles, and squares, respectively, with the fill colors representing the test temperatures as given in the scale bar. The white lines on the temperature scale represent the test temperatures of 223, 233, 248, 261, 300, and $323 \mathrm{~K}$. Porosity error bars are the maximum probable error and, in most cases, are smaller than the symbols; vertical error bars are one SD for each experiment. In each case, the best fit relationships described in the text, with one and two SD ranges, are plotted (for the exponential curve in Figure 7c). Also plotted in Figures $7 \mathrm{a}$ and $7 \mathrm{~b}$ are similar best fit curves plotted for the Rover Opportunity RAT data of Okubo [2007] for rocks in Meridiani Planum. 
Table 2. Parameter Values for Relationships, Referred to Equations in the Text, Between Porosity and UCS ${ }^{\mathrm{a}}$

\begin{tabular}{lcccc}
\hline & \multicolumn{3}{c}{ Parameters - Equation (3) } & Fit \\
\cline { 2 - 4 } & $\sigma_{0}(\mathrm{MPa})$ & $\phi_{\mathrm{c}_{3}}$ & $f_{3}$ & $R^{2}$ \\
\hline This study & $35.35(4.96)$ & $1^{\mathrm{b}}$ & $6.11(2.35)$ & 0.54 \\
Okubo [2007] & $45.77(4.07)$ & $1^{\mathrm{b}}$ & $5.94(0.70)$ & 0.82 \\
\hline
\end{tabular}

${ }^{a}$ Values in parentheses refer to the standard error in the parameter fit.

${ }^{\mathrm{b}}$ Parameter not varied.

Nevada [Schultz and Li, 1995]. This suggests that although sulfate hydrates may, in general, be weaker than lowporosity lava flows [e.g., Heap et al., 2009], they can have similar strength properties to less-coherent volcanic air fall deposits on Mars. Thus, determining the genesis of layers of relatively weak material interstratified with stronger stacked basalt flows observed on Mars [e.g., Okubo and Schultz, 2004] is probably unlikely based on mechanical properties alone.

[25] Our measured values of Young's modulus show trends that are similar to those of UCS, in that they generally match well estimates for layered deposits on Mars [Okubo, 2007] at higher porosities but show significant deviation at porosities less than about $10 \%$. The Young's modulus of pure epsomite at room temperature was calculated to be $E=$ 22.9 $\mathrm{GPa}$ from the measured elastic stiffness coefficients [Fortes, 2005, and references therein]. Our values of the Young's modulus of MS7 are less than $50 \%$ of the value derived from the elastic constants measured by Alexandrov et al. [1963] but are about two orders of magnitude greater than experimentally derived values for natural gypsum with less than 3\% porosity [Hoxha et al., 2006]. We do not know the Young's modulus of either kieserite or meridianiite. However, we have found that the bulk moduli of epsomite and meridianiite, measured using neutron powder diffraction methods on perdeuterated specimens, are very similar, i.e., 22.4 and $22.0 \mathrm{GPa}$ for epsomite and meridianiite, respectively, both at $250 \mathrm{~K}$ [Fortes et al., 2006, 2008b], so we might expect that the Young's modulus of these hydrates will also be similar.

[26] Our mean value of Poisson's ratio both for MS7 ( $\nu=$ $0.12 \pm 0.01)$ and all tests combined $(\nu=0.14 \pm 0.08)$ are less than those determined from the elastic constants $(\nu=0.33$ [Fortes, 2005, and references therein]) and experimentally for gypsum $(0.30<\nu<0.37$ [Hoxha et al., 2006]). The large uncertainty in our porosity-Poisson's ratio relationship means that we cannot draw any firm conclusions. However, the general decrease in Poisson's ratio with porosity could indicate that deformation is due to the pore properties and collapse rather than to the elastic properties of the solid phase material [Hentschel and Page, 2007]. Differences in Young's modulus and Poisson's ratio can arise because of the sample preparation methods (e.g., grain size, microfracturing, purity) and/or test conditions (e.g., temperature, humidity), but in the absence of natural martian sulfate hydrates for testing, synthetic samples offer the best insight into the first-order mechanical properties of similar deposits on Mars. Further experiments are required to determine the possible effects of in situ growth of magnesium sulfate crystals as, for example, interlocking crystal growth in binary systems may lead to a solidification product that is stronger overall [e.g., McCarthy et al., 2007].

[27] In general, it seems that the mechanical properties of crystalline magnesium sulfate hydrates that we have investigated are controlled predominantly by sample porosity rather by than true elastic deformation, which we would expect also to be the case in the upper tens of kilometers of the martian crust. In a single test, Young's modulus increases until pore collapse is complete, wherein crack damage dominates, causing the sample to become weaker and eventually fail. However, the increase in Poisson's ratio during a single test indicates that radial deformation is significant throughout and not just during pore collapse. We would expect Poisson's ratio to remain constant if our samples were undergoing true linear elastic deformation [Gercek, 2007] or to increase if undergoing crack damage [Heap and Faulkner, 2008]. Therefore, it is most likely that the true deformation of our samples is a two-stage process caused by the uniaxial loading regime: (1) initial compression closes oblique pores and cracks, causing an increase in Young's modulus, while allowing axial pores and cracks to remain open or grow, thus causing an increase in Poisson's ratio; and (2) closure of almost all oblique pores and cracks allows for the initiation of crack damage, decreasing Young's modulus, while axial pores and cracks continue to evolve, allowing Poisson's ratio to continue to increase.

[28] Our limited cyclic-stressing tests seem to support this idea. Young's modulus increases with cycle number and, in one case, became roughly constant after the fifth cycle (Figure 9). This behavior is similar to that observed in brittle compression tests on ice, whereby samples strengthened with increasing cycle number, usually reaching a maximum strength after 10 cycles [Iliescu and Schulson, 2002], but in contrast with deformation tests on low-porosity basalt, whereby Young's modulus and Poisson's ratio decreased and increased, respectively, with increasing loading cycle, as a result of oriented axial crack damage alone [Heap et al., 2009]. The cyclic-strengthening observed in our samples is most likely due to the closure of oblique pores and cracks, which, when complete, allows deformation and failure to proceed in the same way as during a single loading test. Compaction through pore closure and collapse is also supported by the unrecoverable strain evident during the cyclic stressing test shown in Figure 9b, which is indicative of an almost completely inelastic deformation mechanism. This idea of pore collapse during testing is also supported by the postdeformation SEM images in Figure 2, which show that, after a deformation test, there has been a reduction in both the pore size and the density in a representative MS1.25 sample. These SEM images also show some possible deformation-related grain orientation, although further

Table 3. Parameter Values for Relationships, Referred to Equations in the Text, Between Porosity and Young's Modulus ${ }^{\mathrm{a}}$

\begin{tabular}{lllll}
\hline & \multicolumn{3}{c}{ Parameters - Equation (4) } & Fit \\
\cline { 2 - 4 } & $E_{0}(\mathrm{GPa})$ & $\phi_{\mathrm{c}_{4}}$ & \multicolumn{1}{c}{$f_{4}$} & $R^{2}$ \\
\hline This study & $6.48(0.66)$ & $1^{\mathrm{b}}$ & $4.05(1.29)$ & 0.63 \\
Okubo [2007] & $23.36(3.47)$ & $1^{\mathrm{b}}$ & $16.86(2.69)$ & 0.87 \\
\hline
\end{tabular}

\footnotetext{
${ }^{\mathrm{a}}$ Values in parentheses refer to the standard error in the parameter fit.
}

${ }^{\mathrm{b}}$ Parameter not varied. 
Table 4. Parameter Values for Relationships, Referred to Equations in the Text, Between Porosity and Poisson's Ratio ${ }^{\text {a }}$

\begin{tabular}{|c|c|c|c|c|c|c|c|c|c|c|c|}
\hline & \multicolumn{7}{|c|}{ Spherical Pores } & \multirow{3}{*}{$\frac{\text { Fit }}{R^{2}}$} & \multirow{2}{*}{\multicolumn{2}{|c|}{$\begin{array}{c}\text { Exponential } \\
\text { Parameters - Equation (6) }\end{array}$}} & \multirow{3}{*}{$\frac{\text { Fit }}{R^{2}}$} \\
\hline & \multicolumn{7}{|c|}{ Parameters - Equation (5) } & & & & \\
\hline & $\nu_{0}$ & $a_{5}$ & $b_{5}$ & $c_{5}$ & $d_{5}$ & $K_{\mathrm{p}, 1}$ & $K_{\mathrm{p}, 2}$ & & $a_{6}$ & $b_{6}$ & \\
\hline This study & 0.02 & -35.0 & -4.5 & 9.0 & 2.1 & 0.27 & 1.0 & 0.71 & $0.44(0.003)$ & $-1.05(0.332)$ & 0.75 \\
\hline
\end{tabular}

${ }^{a}$ Values in parentheses refer to the standard error in the parameter fit. Parameters in the spherical pore fit are essentially unconstrained.

experimental work is required to determine the exact nature of the evolution of grain isotropy with respect to the principal stress axes.

\subsection{Implications for Magnesium Sulfate Hydrates on Mars}

[29] The mechanical properties determined here do not necessarily help determine the conditions under which sulfate hydrates form, but they do help us understand how similar deposits would have behaved since their formation. Any wall slope is only as strong as the weakest layer present, and thus, to a large extent, the stability and possible collapse of walls that contain even relatively thin layers of sulfate hydrates will be governed by the strength of those
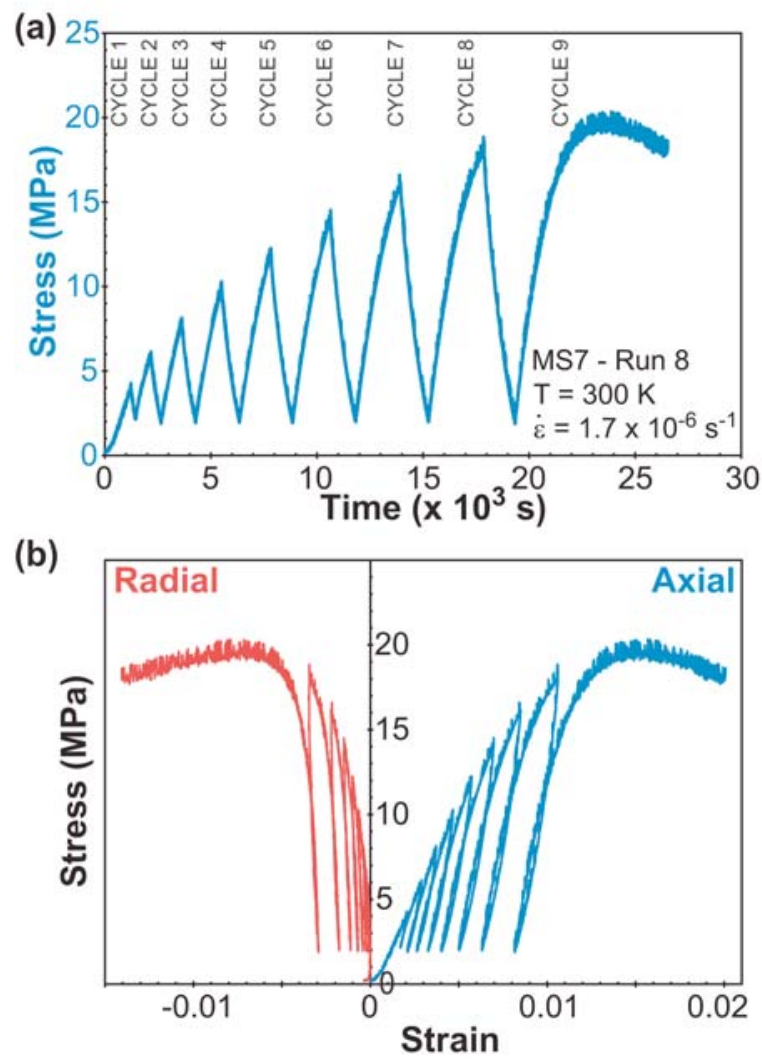

Figure 8. Example of cyclic stressing results with an MS7 sample (run 8) loaded and unloaded at a strain rate of $1.7 \times$ $10^{-6} \mathrm{~s}^{-1}$ at $300 \mathrm{~K}$. (a) Loading path showing the increasing stress amplitude procedure, with each loading and unloading portion of a cycle indicated. The sample failed during the ninth cycle. (b) Stress as a function of radial and axial strain, showing significant dilatancy. deposits. In East Candor Chasma, alternating layers of kieserite and polyhydrated sulfates have been observed in CRISM data, with the kieserite beds having steeper slopes than those of the polyhydrated layers [Roach et al., 2008; Murchie et al., 2009]. The relative steepness of the alternating layers is unlikely to be controlled by the original formation method and is more likely representative of the postdepositional evolution of the layers. In this case, the steeper kieserite walls are probably indicative of greater bulk strength than for the polyhydrated layers, which could be due to the porosity effects (the kieserite could be stronger because of a lower porosity than the polyhydrates) and/or inherent differences associated with hydration state (if porosity is homogenous throughout the layers, then there
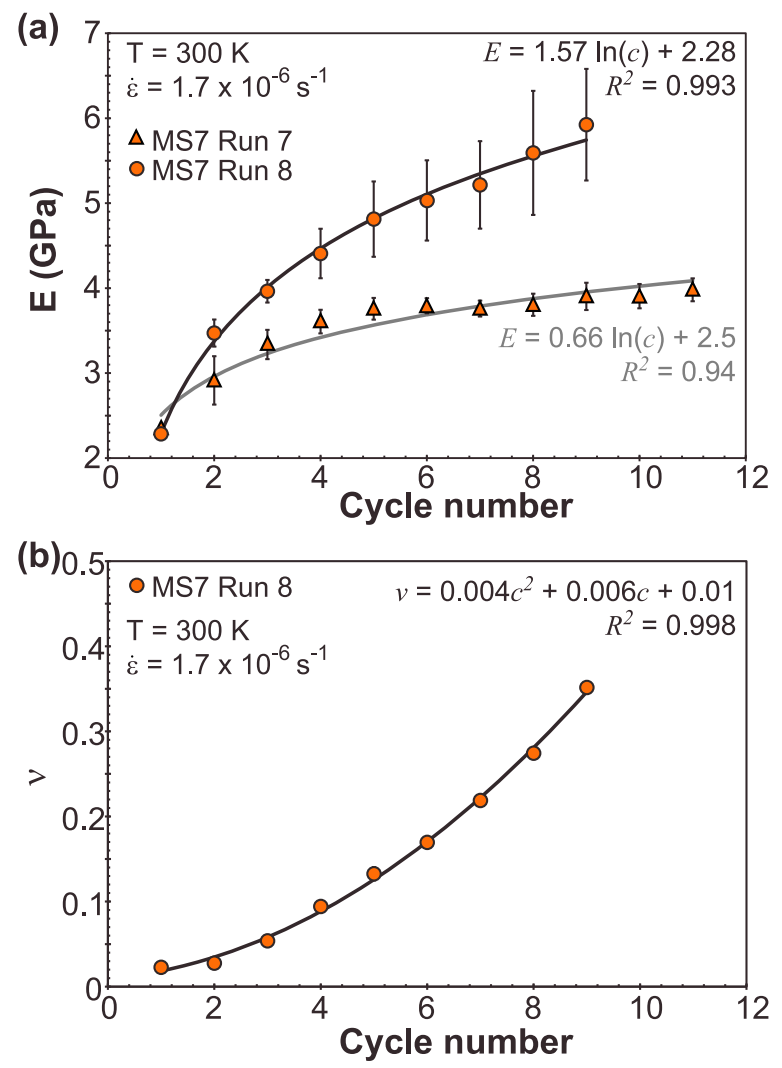

Figure 9. Evolution of elastic moduli with increasing cycling stressing. (a) Mean Young's modulus of the quasielastic loading portion for both MS7 runs 7 (triangles) and 8 (circles) as a function of cycle number. (b) Mean Poisson's ratio of the quasielastic loading portion for MS7 run 8. Error bars in this case are smaller than the data points. In each case, experimental conditions are given in addition to nominal fits to experimental data. 
(a)

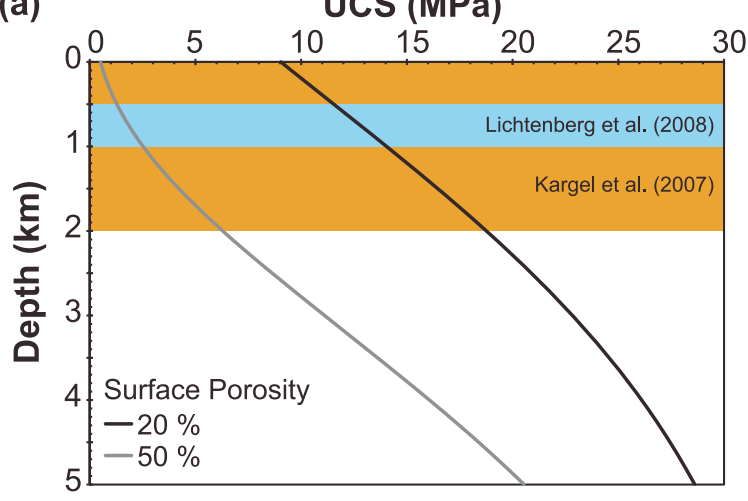

(b)

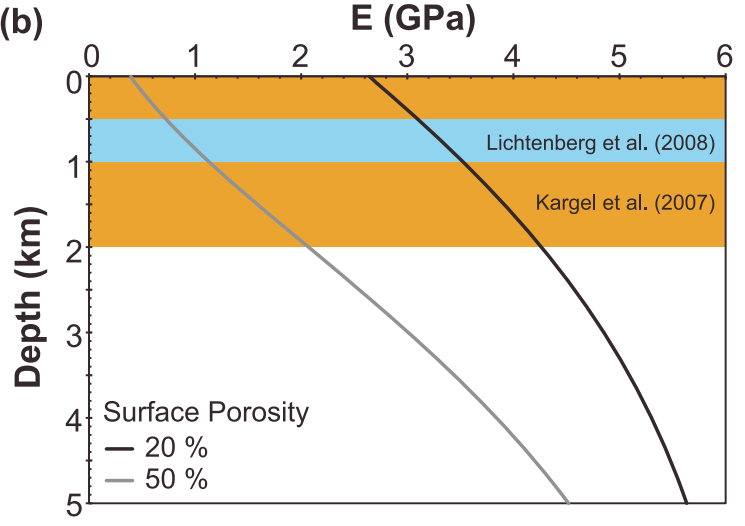

(c)

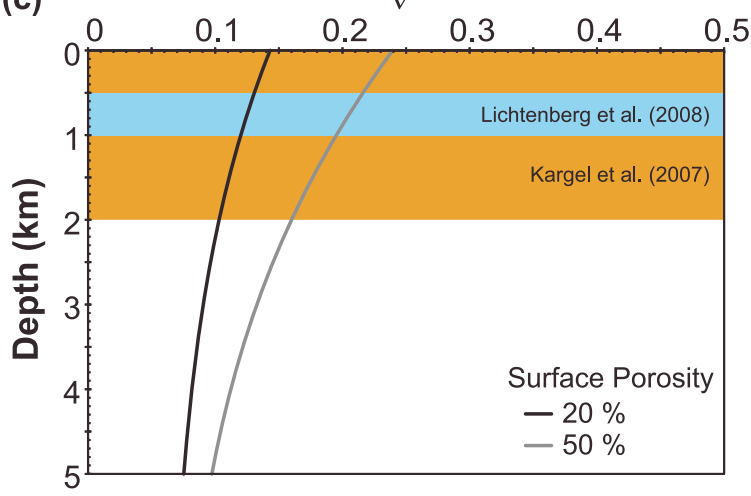

Figure 10. Mechanical properties as a function of depth on Mars. In each case, the (a) UCS, (b) Young's modulus, and (c) Poisson's ratio are plotted as a function of depth using the porosity relationships derived in this study (see text), and the depth-porosity relationship given by Clifford [1993]. Also indicated are the levels at which sulfate hydrates have been suggested [Kargel et al., 2007] or observed [Lichtenberg et al., 2008] to occur as large deposits on Mars.

must be a hydration-strength relationship not quantified in this study). Further experiments on different hydrates of similar porosities, or one of more hydrates with a range of porosities, are required to address this uncertainty.

[30] The porosity of sulfate-rich deposits at the martian surface has been estimated from Opportunity RAT data [Okubo, 2007], but it can also be predicted as a function of depth using theoretical depth-porosity relationships. Figure 10 shows the mechanical properties determined in this study plotted as a function of the depth-porosity relationships given by Clifford [1993]. In this figure, we use the porosity-relationships for UCS, Young's modulus, and Poisson's ratio given by equations (3), (4), and (6), respectively. We consider the two cases of Clifford [1993], with surface porosities of $20 \%$ and $50 \%$, with porosity increasing with depth according to an exponential relationship. It is evident that, with all other factors being equal, the UCS and Young's modulus of magnesium sulfate hydrates, both increase with depth, as a result of the reduced porosity, whereas Poisson's ratio decreases. Surface porosities of close to $50 \%$ have been observed for the RAT grind target Virginia, with the resultant predicted UCS and Young's modulus of this rock being $3.55 \mathrm{MPa}$ and $0.42 \mathrm{GPa}$, respectively [OKubo, 2007]. Our predicted surface values of UCS and Young's modulus at $50 \%$ porosity are more than double those predicted for Virginia, indicating that the shale analog might not be appropriate at these high porosities and/ or that local factors such as preferred orientation or grain size might play a role in weakening the sulfate-rich rocks at Meridiani Planum. Thus, at the surface, our results probably best represent maximum values of mechanical properties of sulfate hydrates, which could be applied to gypsum dunes observed in the North Polar region [Langevin et al., 2005]. However, the most extensive deposits of magnesium sulfate hydrates have been observed by orbiting infrared spectrometers to occur at near-equatorial latitudes. Observations by the OMEGA instrument onboard the Mars Express spacecraft show the global distribution of hydrated minerals on Mars and indicate large-scale concentrations of hydrated deposits in Valles Marineris and chaos regions [e.g., Bibring et al., 2006]. The OMEGA observations serve as an effective context for higher spatial resolution, multispectral images obtained by the CRISM instrument onboard Mars Reconnaissance Orbiter. Recent CRISM observations have identified outcrops of polyhydrated sulfate-rich layers in Aram Chaos, occurring in a $500 \mathrm{~m}$ thick deposit, which are overlain by approximately $500 \mathrm{~m}$ of an erosion-resistant cap unit [Lichtenberg et al., 2008]. This band of sulfate hydrate deposit is plotted as a function of depth in Figure 10 to illustrate how our results can be of use to future studies concerned with the strength and stability of similar deposits on Mars. For example, at depths similar to those observed at Aram Chaos, any layers dominated by sulfate hydrates could have strength properties significantly higher than expected for similar deposits at the surface. Thick hydrate layers have also been predicted to occur at greater depths on Mars. Kargel et al. [2007] invoke thermally insulating salt and gas hydrate lenses $1 \mathrm{~km}$ thick, with upper surfaces at depths of up to $2 \mathrm{~km}$, as being responsible for hydrologic processes such as chaos or gully formation. The mechanical behavior and ultimate collapse involved in such a process will be at least partially governed by the mechanical properties of the hydrates involved, in addition to other factors such as compositionally induced freezing point depressions and the local geothermal regime [Kargel et al., 2007]. Our results are important in such studies, although further experiments are required to investigate the effect of confining pressure on the mechanical properties of sulfate hydrates.

[31] Although we are mainly concerned with brittle deformation in this study, the inelastic ductile behavior observed in a small number of tests, even at relatively high 
strain rates under uniaxial conditions, could be indicative of the propensity of these hydrates to undergo time-dependent deformation [Durham et al., 2005] or pressure-induced melting [Hogenboom et al., 1995]. The ductile deformation of anhydrous and hydrous salts is an important process on the Earth, forming diapiric intrusions and hydrocarbon traps, and there is evidence for similar deformation mechanisms operating on Mars at both local and regional scales despite the lower temperatures. HiRISE imagery reveals fold and thrust fault structures, on the order of hundreds of meters to kilometers, in interior layered deposits in SW Candor Chasma [Okubo et al., 2008; Okubo, 2010], indicative of combined ductile and brittle processes, respectively. Our observation of ductile behavior in meridianiite at low temperatures under uniaxial load suggests that similar deposits on Mars could deform in a ductile manner under presentday surface conditions. Ductile creep could occur in sulfate hydrates at lower strain rates than considered in this study if the confining pressure was increased [Durham et al., 2005]. The ductile behavior of salts has also been implicated in regional-scale gravity spreading in the Thaumasia Plateau region of Mars [Montgomery et al., 2009]. The elevated pressure and temperature at the depths required for this gravity spreading model will increase the likelihood of ductile deformation in magnesium sulfate hydrates, and hydrates in general, even at low strain rates, because our results show that ductile creep can begin at driving stresses as low as $\sim 15 \mathrm{MPa}$ (Figure 5).

[32] Our cyclic stressing tests can be related qualitatively to periods of changing obliquity on Mars through responses both external and internal to deposits of sulfate hydrates. Cyclic stressing of sulfate hydrate layers could occur on Mars owing to the response of the atmosphere to obliquityrelated insolation changes [e.g., Laskar et al., 2002, 2004]. Atmospheric deposition of dust and/or ice at low latitudes during periods of high obliquity could increase the load on preexisting layers; for example, an average deposition rate of $0.05 \mathrm{~cm} \mathrm{yr}^{-1}$ [Laskar et al., 2002] during 10 Ma yields an overlying deposit $5 \mathrm{~km}$ thick, giving rise to a confining load of $\sim 30 \mathrm{MPa}$. Obviously, during periods of low obliquity, aeolian erosion and sublimation of ice will remove some of the deposited material, hence reducing the load. Similar periods of cyclic loading could also occur through periodic burial of sulfate hydrate deposits by lava flows or impact ejecta, although regularly cyclic bedding observed at the poles [Laskar et al., 2002] and low latitudes [Lewis et al., 2008] appears to rule out such stochastic processes for these deposits. The intrinsic properties of sulfate hydrate deposits, such as thermal expansivity, conductivity, and gas diffusivity, would also respond to obliquity-related temperature and humidity changes regardless of depositional loading. Our results suggest that, although cyclic loading might not immediately change the overall strength of sulfate hydrate layers on Mars, this cyclicity will affect the porosity, and hence the long-term strength and water-storing capacity of these deposits.

\section{Conclusions}

[33] We have carried out uniaxial compression experiments on stable phases in the magnesium sulfate-water system to determine the mechanical properties of similar deposits on Mars. In this study, we attempted to measure UCS, Young's modulus, and Poisson's ratio. Our synthetic samples of kieserite (MS1.25), epsomite (MS7), and meridianiite (MS11) have mean porosity values of $47.6 \%$, $11.4 \%$, and $2.9 \%$, respectively, and mean UCS values of $6.3 \pm 0.7,12.9 \pm 1.8$, and $30.1 \pm 4.5 \mathrm{MPa}$, respectively. As a system, magnesium sulfate hydrates seem to have strengths that are controlled predominantly by the sample porosity, showing a negative trend with UCS. Young's modulus also shows a similar relationship with porosity, with MS1.25, MS7, and MS11 having mean Young's modulus values of $0.8 \pm 0.1,2.9 \pm 0.4$, and $5.9 \pm 0.8 \mathrm{GPa}$, respectively. We successfully measured Poisson's ratio in only $20 \%$ of our tests, resulting in errors sufficiently large to preclude determination of a relationship with porosity with any confidence. Porosity was measured using relative density analysis and, in representative samples, verified with other methods including fluid saturation and gas displacement.

[34] Although our tests were unable to quantify any systematic relationship between hydration state and mechanical properties, the different porosities produced by consistent sample preparation methods suggest that the addition of non-cation-coordinated water molecules likely reduces the bulk strength of sulfate hydrates. We expect that the mechanical properties of sulfate hydrate deposits on Mars will be dominated by the bulk porosity rather than by the strength of the pure solid phase. Further experimental work is required to produce different hydrate phases of similar porosities, or vice versa, to identify any possible hydrationrelated strength relationship for application to alternating layers of sulfate hydrates as wall rock on Mars. Future experiments should also address the possibility of pressureinduced incongruous melting, which could lead to ductile behavior, at temperatures below those expected at the respective melting temperatures of the different hydrate phases.

[35] To simulate possible obliquity-related depositional and erosional periods on Mars, we also carried out some cyclic stressing tests. The three samples used in the cyclic tests showed similar bulk mechanical properties to those in the single loading tests, although a gradual compaction and reduction in sample porosity, rather than just an increase in crack damage, was observed with each loading cycle. Applying these preliminary cyclic results to similar deposits on Mars suggests that any obliquity-related evolution of mechanical properties will depend on local factors such as bulk density, porosity, and, hence, formation mechanism, in addition to the overall stress history.

[36] Acknowledgments. P.M.G. is funded by an STFC Aurora Fellowship (ST/F011830/1), M.J.H. is funded by a NERC studentship (NER/S/A2005/13553), and A.D.F. is funded by an STFC Advanced Fellowship (PP/E006515/1). The authors thank John Bowles, Neil Hughes, Steve Boon, and James Davy for technical support throughout the study and Judith Zhou for assistance with using the pycnometer. The authors also thank Chris Okubo and an anonymous reviewer for detailed reviews that greatly improved the paper and Robert Carlson for editorial handling.

\section{References}

Alexandrov, K. S., T. V. Rhyzhova, and A. I. Rostuntseva (1963), Elastic properties of some sulfate heptahydrate crystals, Sov. Phys. Crystallogr., 7, 753-755. 
Aleksovska, S., V. M. Petrusevski, and B. Soptrajanov (1998), Calculation of structural parameters in isostructural series: The kieserite group, Acta Cryst. B., 54, 564-567, doi:10.1107/S0108768198000974.

Arvidson, R. E., et al. (2004), Localization and physical property experiments conducted by Opportunity at Meridiani Planum, Mars, Science, 306, 1730-1733, doi:10.1126/science.1104211.

Avrami, M. (1939), Kinetics of phase change I, J. Chem. Phys., 7, 11031112, doi:10.1063/1.1750380.

Bell, F. G. (2000), Engineering Properties of Soils and Rocks, 4th ed., 482 pp., Wiley-Blackwell, Oxford, UK

Bibring, J.-P., Y. Langevin, J. F. Mustard, F. Poulet, R. Arvidson, A. Gendrin B. Gondet, N. Mangold, P. Pinet, and F. Forget (2006), Global mineralogical and aqueous Mars history derived from OMEGA/Mars Express data, Science, 312, 400-404, doi:10.1126/science.1122659.

Bishop, J. L., et al. (2008), Characterization of light-toned sulfate and hydrated silica layers at Juventae Chasma using CRISM, OMEGA, HiRISE, and Context images, Lunar Planet. Sci., XXXIX, Abstract 2334.

Boynton, W. V., et al. (2002), Distribution of hydrogen in the near surface of Mars: Evidence for subsurface ice deposits, Science, 297, 81-85, doi:10.1126/science.1073722.

Bredthauer, R. O. (1957), Strength characteristics of rock samples under hydrostatic pressure, Trans. ASME, 122, 1049-1068.

Catling, D. C., S. E. Wood, C. Leovy, D. R. Montgomery, H. M. Greenberg, C. R. Glein, and J. M. Moore (2006), Light-toned layered deposits in Juventae Chasma, Mars, Icarus, 181, 26-51, doi:10.1016/j.icarus 2005.10.020.

Chapman, M. G., and K. L. Tanaka (2001), Interior trough deposits on Mars: Subice volcanoes?, J. Geophys. Res., 106(E5), 10,087-10,100, doi:10.1029/2000JE001303.

Chang, C., M. D. Zoback, and A. Khaksar (2006), Empirical relations between rock strength and physical properties in sedimentary rocks, J. Pet. Sci. Eng., 51, 223-237, doi:10.1016/j.petrol.2006.01.003.

Chipera, S. J., and D. T. Vaniman (2007), Experimental stability of magnesium sulfates that may be present on Mars, Geochim. Cosmochim. Acta., 71, 241-250, doi:10.1016/j.gca.2006.07.044

Chou, I.-M., and R. R. Seal II (2007), Magnesium and calcium sulfate stabilities and the water budget of Mars, J. Geophys. Res., 112, E11004, doi:10.1029/2007JE002898.

Christensen, P. R., et al. (2000), Detection of crystalline hematite mineralization on Mars by the Thermal Emission Spectrometer: Evidence for near-surface water, J. Geophys. Res., 105(E4), 9623-9642, doi:10.1029/1999JE001093.

Clifford, S. M. (1993), A model for the hydrologic and climatic behavior of water on Mars, J. Geophys. Res., 98(E6), 10,973-11,016, doi:10.1029/ 93JE00225.

Clifford, S. M., et al. (2000), The state and future of Mars polar science and exploration, Icarus, 144, 210-242, doi:10.1006/icar.1999.6290.

Cox, S. J. D., and P. G. Meredith (1993), Microcrack formation and material softening in rock measured by monitoring acoustic emissions, Int. J. Rock Mech. Min. Sci. Geomech. Abstr., 30, 11-24.

de Meer, S., and C. J. Spiers (1995), Creep of wet gypsum aggregates under hydrostatic loading conditions, Tectonophysics, 245, 171-183, doi:10.1016/0040-1951(94)00233-Y.

Durham, W. B., L. A. Stern, T. Kubo, and S. H. Kirby (2005), Flow strength of highly hydrated $\mathrm{Mg}$ - and $\mathrm{Na}$-sulfate hydrate salts, pure and in mixtures with water ice, with application to Europa, J. Geophys. Res., 110, E12010, doi:10.1029/2005JE002475.

Emons, H.-H., G. Ziegenbalg, R. Naumann, and F. Paulik (1990), Thermal decomposition of the magnesium sulphate hydrates under quasi-isotherma and quasi-isobaric conditions, J. Therm. Anal., 36, 1265-1279, doi:10.1007/ BF01914050.

Faulkner, D. R., T. M. Mitchell, D. Healy, and M. J. Heap (2006), Slip on 'weak' faults by the rotation of regional stress in the fracture damage zone, Nature, 444, 922-925, doi:10.1038/nature05353.

Feldman, W. C., et al. (2004), Global distribution of near-surface hydrogen on Mars, J. Geophys. Res., 109, E09006, doi:10.1029/2003JE002160.

Fortes, A. D. (2005), From Surrey to the moons of Jupiter (via Mars): The story of epsomite, Axis, 1, 1-28.

Fortes, A. D., I. G. Wood, M. Alfredsson, L. Vočadlo, and K. S. Knigh (2006), The thermoelastic properties of $\mathrm{MgSO}_{4} \cdot 7 \mathrm{D}_{2} \mathrm{O}$ (epsomite) from powder neutron diffraction and ab initio calculation, Eur. J. Mineral., 18 , 449-462, doi:10.1127/0935-1221/2006/0018-0449.

Fortes, A. D., I. G. Wood, and K. S. Knight (2008a), The crystal structure and thermal expansion tensor of $\mathrm{MgSO}_{4} \cdot 11 \mathrm{D}_{2} \mathrm{O}$ (meridianiite) determined by neutron powder diffraction, Phys. Chem. Miner., 35, $207-$ 221, doi:10.1007/s00269-008-0214-x.
Fortes, A. D., I. G. Wood, H. E. A. Brand, and K. S. Knight (2008b), Highpressure study of triclinic $\mathrm{MgSO}_{4} \cdot 11 \mathrm{D}_{2} \mathrm{O}$, in ISIS Experimental Report RB810006.

Gendrin, A., et al. (2005), Sulfates in Martian layered terrains: The OMEGA Mars Express view, Science, 307, 1587-1591, doi:10.1126/science. 1109087.

Gercek, H. (2007), Poisson's ratio values for rocks, Int. J. Rock Mech. Min. Sci., 44, 1-13, doi:10.1016/j.ijrmms.2006.04.011.

Hawkes, I., and M. Mellor (1970), Uniaxial testing in rock mechanics laboratories, Eng. Geol., 4, 177-285, doi:10.1016/0013-7952(70)90034-7.

Heap, M. J., and D. R. Faulkner (2008), Quantifying the evolution of static elastic properties as crystalline rock approaches failure, Int. J. Rock Mech. Min. Sci., 45, 564-573, doi:10.1016/j.ijrmms.2007.07.018.

Heap, M. J., S. Vinciguerra, and P. G. Meredith (2009), The evolution of elastic moduli with increasing crack damage during cyclic stressing of a basalt from Mt. Etna volcano, Tectonophysics, 471, 153-160, doi:10.1016/j.tecto.2008.10.004.

Hentschel, M. L., and N. W. Page (2007), Elastic properties of powders during compaction: Part 1. Pseudo-isotropic moduli, J. Mater. Sci., 42, 1261-1268, doi:10.1007/s10853-006-1145-x

Hogenboom, D. L., J. S. Kargel, J. P. Ganasan, and L. Lee (1995), Magnesium sulfate-water to $400 \mathrm{MPa}$ using a novel piezometer: Densities, phase equilibria, and planetological implications, Icarus, 115, 258-277, doi:10.1006/icar.1995.1096.

Horgan, B. H., J. F. Bell III, E. Z. Noe Dobrea, E. A. Cloutis, D. T. Bailey, M. A. Craig, L. H. Roach, and J. F. Mustard (2009), Distribution of hydrated minerals in the north polar region of Mars, J. Geophys. Res., 114, E01005, doi:10.1029/2008JE003187.

Horsund, P. (2001), Estimating mechanical properties of shale from empirical correlations, SPE Drill. Complet., 16, 68-73.

Hoxha, D., F. Homand, and C. Auvray (2006), Deformation of natural gypsum rock: Mechanisms and questions, Eng. Geol., 86, 1-17, doi:10.1016/ j.enggeo.2006.04.002

Iliescu, D., and E. M. Schulson (2002), Brittle compressive failure of ice: Monotonic versus cyclic loading, Acta. Mater., 50, 2163-2172, doi:10.1016/S1359-6454(02)00060-5

International Society of Rock Mechanics (1978), Suggested methods for determining the uniaxial compressive strength and deformability of rock materials, Int. J. Rock Mech. Min. Sci. Geomech. Abstr., 16, 135-140.

Jaeger, J. C., N. G. W. Cook, R. W. Zimmerman (2007), Fundamentals of Rock Mechanics, 4th ed., 488 pp., Blackwell, Oxford, UK.

Kargel, J. S., R. Furfaro, O. Pieto-Ballesteros, J. A. P. Rodriguez, D. R. Montgomery, A. R. Gillespie, G. M. Marion, and S. E. Wood (2007), Martian hydrogeology sustained by thermally insulating gas and salt hydrates, Geology, 35, 975-978, doi:10.1130/G23783A.1.

Kieffer, H. H., S. C. Chase, E. D. Miner, F. D. Palluconi, G. Münch, G. Neugebauer, and T. Z. Martin (1976), Infrared thermal mapping of the Martian surface and atmosphere: First results, Science, 193, 780-786, doi:10.1126/science.193.4255.780.

Komatsu, G., G. G. Ori, P. Ciarcelluti, and Y. D. Litasov (2004), Interior layered deposits of Valles Marineris, Mars: Analogous subice volcanism related to Baikal Rifting, Southern Siberia, Planet. Space Sci., 52, 167187, doi:10.1016/j.pss.2003.08.003

Lamy, P., L. Brunet, and G. Thomas (2005), Modeling the porosity evolution of a powder under uniaxial compression, Propellants Explos. Pyrotech., 30, 397-403, doi:10.1002/prep.200500031.

Langevin, Y., F. Poulet, J.-P. Bibring, and B. Gondet (2005), Sulfates in the north polar region of Mars detected by OMEGA/Mars Express, Science, 307, 1584-1586, doi:10.1126/science.1109091.

Lashkaripour, G. R., and M. B. Dusseault (1993), A statistical study on shale properties: Relationship among principal shale properties, in Probabilistic Methods in Geotechnical Engineering: Proceedings of the Conference on Probabilistic Methods in Geotechnical Engineering Canberra-Australia - 10-12 February, 1993, edited by K. S. S. Li and S. C. Lo, pp. 195-200, A. A. Balkema, Rotterdam, Netherlands.

Laskar, J., B. Levrard, and J. F. Mustard (2002), Orbital forcing of the Martian polar layered deposits, Nature, 419, 375-377, doi:10.1038/nature01066.

Laskar, J., A. C. M. Correia, M. Gastineau, F. Joutel, B. Levrard, and P. Robutel (2004), Long term evolution and chaotic diffusion of the insolation quantities of Mars, Icarus, 170, 343-364, doi:10.1016/j.icarus. 2004.04.005.

Lewis, K. W., O. Aharonson, J. P. Grotzinger, R. L. Kirk, A. S. McEwen, and T.-A. Suer (2008), Quasi-periodic bedding in the sedimentary rock record of Mars, Science, 322, 1532-1535, doi:10.1126/science.1161870.

Liang, W., C. Yang, Y. Zhao, M. B. Dusseault, and J. Liu (2007), Experimental investigation of mechanical properties of bedded salt rock, Int. J Rock Mech. Min. Sci., 44, 400-411, doi:10.1016/j.ijrmms.2006.09.007. 
Liang, W., and Y. Zhao (2004), Experimental study on mechanical characteristics of thenardite rock salt, Chin. J. Rock Mech. Eng., 23, 391-394, doi:10.1007/s00603-005-0067-2.

Lichtenberg, K., R. Arvidson, J. Bishop, T. Glotch, E. Noe Dobrea, S. Murchie, J. Mustard, and L. Roach (2008), Mg- and Fe-Sulfate Layers in Aram Chaos, Mars, Eos Trans. AGU, 89(53), Fall Meet. Suppl., Abstract P44A-09.

Ma, H., D. L. Bish, H.-W. Wang, and S. J. Chipera (2009), Determination of the crystal structure of sanderite, $\mathrm{MgSO}_{4} \cdot 2 \mathrm{H}_{2} \mathrm{O}$, by X-ray powder diffraction and the charge flipping method, Am. Mineral., 94, 622-625, doi:10.2138/am.2009.3110.

Mangold, N., A. Gendrin, B. Gondet, S. LeMouelic, C. Quantin, V. Ansan, J.-P. Bibring, Y. Langevin, P. Masson, and G. Neukum (2008), Spectra and geological study of the sulfate-rich region of West Candor Chasma, Mars, Icarus, 194, 519-543, doi:10.1016/j.icarus.2007.10.021.

McCarthy, C., R. F. Cooper, S. H. Kirby, K. D. Rieck, and L. A. Stern (2007), Solidification and microstructures of binary ice-I/hydrate eutectic aggregates, Am. Mineral., 92, 1550-1560, doi:10.2138/am.2007.2435.

Mellon, M. T., B. M. Jakosky, and S. E. Postawko (1997), The persistence of equatorial ground ice on Mars, J. Geophys. Res., 102(E8), 19,35719,369, doi:10.1029/97JE01346.

Mogi, K. (1966), Some precise measurements of fracture strength of rocks under uniform compressive stress, Felsmech. Ingenieurgeol., 4, 41-55.

Montgomery, D. R., S. M. Som, M. P. A. Jackson, B. C. Schreiber, A. R Gillespie, and J. B. Adams (2009), Continental-scale salt tectonics on Mars and the origin of Valles Marineris and associated outflow channels, Geol. Soc. Am. Bull., 121, 117-133, doi:10.1130/B26307.1.

Murchie, S., et al. (2009), Evidence for the origin of layered deposits in Candor Chasma, Mars, from mineral composition and hydrologic modeling, J. Geophys. Res., 115, E00D05, doi:10.1029/2009JE003343.

Murrell, S. A. F., and S. Chakravarty (1973), Some new rheological experiments on igneous rocks at temperatures up to $1120^{\circ} \mathrm{C}$, Geophys. J. R Astron. Soc., 34, 211-250.

Olgaard, D., S. Ko, and T. Wong (1995), Deformation and pore pressure in dehydrating gypsum under transiently drained conditions, Tectonophysics, 245, 237-248, doi:10.1016/0040-1951(94)00237-4.

Okubo, C. H. (2007), Strength and deformability of light-toned layered deposits observed by MER Opportunity: Eagle to Erebus craters, Mars, Geophys. Res. Lett., 34, L20205, doi:10.1029/2007GL031327.

Okubo, C. H. (2010), Structural geology of Amazonian-aged layered sedimentary deposits in southwest Candor Chasma, Mars, Icarus, doi:10.1016/j.icarus.2009.11.012, in press.

Okubo, C. H., and R. A. Schultz (2004), Mechanical stratigraphy in the western equatorial region of Mars based on thrust fault-related fold topography and implications for near-surface volatile reservoirs, Geol. Soc. Am. Bull., 116, 594-605, doi:10.1130/B25361.1.

Okubo, C. H., K. W. Lewis, A. S. McEwen, and R. L. Kirk (2008), Relative age of interior layered deposits in southwest Candor Chasma based on high-resolution structural mapping, J. Geophys. Res., 113, E12002, doi:10.1029/2008JE003181.

Papadopoulos, Z., E. Kolaiti, and N. Mourtzas (1994), The effect of crystal size on geotechnical properties of Neogene in Crete, Q. J. Eng. Geol., 27 267-273, doi:10.1144/GSL.QJEGH.1994.027.P3.07.

Paterson, M. S., and T.-F. Wong (2005), Experimental Rock Deformation: The Brittle Field, 348 pp., Springer, Berlin.

Peterson, R. C., and R. Wang (2006), Crystal molds on Mars: Melting of a possible new mineral species to create Martian chaotic terrain, Geology, 34, 957-960, doi:10.1130/G22678A.1.

Phani, K. K., and S. K. Niyogi (1987), Young's modulus of porous brittle solids, J. Mater. Sci., 22, 257-263, doi:10.1007/BF01160581.

Phani, K. K., and D. Sanyal (2005), Critical reevaluation of the prediction of effective Poisson's ratio for porous materials, J. Mater. Sci., 40, 5685 5690, doi:10.1007/s10853-005-1507-9.
Renshaw, C. E, and E. M. Schulson (2001), Universal behavior in compressive failure of brittle materials, Nature, 412, 897-900, doi:10.1038/ 35091045

Roach, L. H., J. F. Mustard, S. L. Murchie, J.-P. Bibring, R. E. Arvidson, J. L. Bishop, R. E. Milliken, F. Seelos (2008), Constraints on the rate of sulfate phase changes in Valles Marineris Interior Layered Deposits, Lunar Planet. Sci. Conf., XXXIX, Abstract 1891.

Rocchi, V., P. R. Sammonds, and C. R. J. Kilburn (2002), Flow and fracture maps for basaltic rock deformation at high temperatures, $J$. Volcanol. Geotherm. Res., 120, 25-42, doi:10.1016/S0377-0273(02)00343-8.

Rohde, J., and H. Feng (1990), Analysis of the variability of unconfined compression tests of rocks, Rock Mech. Rock Eng., 23, 231-236, doi:10.1007/BF01022955.

Schulson, E. M. (2001), Brittle failure of ice, Eng. Fract. Mech., 68, 1839 1887, doi:10.1016/S0013-7944(01)00037-6.

Schultz, R. A. (1993), Brittle strength of basaltic rock masses with application to Venus, J. Geophys. Res., 98(E6), 10,883-10,895, doi:10.1029/ 93JE00691.

Schultz, R. A. (1995), Limits on strength and deformation properties of jointed basaltic rock masses, Rock Mech. Rock Eng., 28, 1-15, doi:10.1007/BF01024770.

Schultz, R. A. (2002), Stability of rock slopes in Valles Marineris, Mars, Geophys. Res. Lett., 29(19), 1932, doi:10.1029/2002GL015728.

Schultz, R. A., and Q. Li (1995), Uniaxial strength testing of non-welded Calico Hills tuff, Yucca Mountain, Nevada, Eng. Geol., 40, 287-299, doi:10.1016/0013-7952(95)00041-0.

Squyres, S. W., et al. (2004), In situ evidence for an ancient aqueous environment at Meridiani Planum, Mars, Science, 306, 1709-1714, doi:10.1126/science.1104559.

Titus, T. N., H. H. Kieffer, and P. R. Christensen (2003), Exposed water ice discovered near the south pole of Mars, Science, 299, 1048-1051, doi:10.1126/science. 1080497 .

Tuffen, H., R. Smith, and P. Sammonds (2008), Evidence for seismogenic fracture of silicic magma, Nature, 253, 511-514, doi:10.1038/ nature06989.

Vaniman, D. T., and S. J. Chipera (2006), Transformations of Mg- and Ca-sulfate hydrates in Mars regolith, Am. Mineral., 91, 1628-1642, doi:10.2138/am.2006.2092.

Wachter, L. M., C. E. Renshaw, and E. M. Schulson (2009), Transition in brittle failure mode in ice under low confinement, Acta Mater., 57, 345355, doi:10.1016/j.actamat.2008.09.021.

Wang, A., J. J. Freeman, and B. L. Jolliff (2009), Phase transition pathways of the hydrates of magnesium sulfate in the temperature range $50^{\circ} \mathrm{C}$ to $5^{\circ} \mathrm{C}$ : Implication for sulfates on Mars, J. Geophys. Res., 114, E04010, doi:10.1029/2008JE003266

Washburn, E. W. (1921), The dynamics of capillary flow, Phys. Rev., 17, 273-283, doi:10.1103/PhysRev.17.273.

A. D. Fortes, P. M. Grindrod, and P. R. Sammonds, Department of Earth Sciences, University College London, Gower Street, London WC1E 6BT, UK. (p.grindrod@ucl.ac.uk)

M. J. Heap, Department of Earth and Environmental Sciences, Section for Mineralogy, Petrology and Geochemistry, Ludwig-MaximiliansUniversität München, Geschwister-Scholl-Platz 1, 80539 Munich, Germany.

P. G. Meredith and I. G. Wood, Rock and Ice Physics Laboratory, Research School of Geological and Geophysical Sciences, University College London, Gower Street, London, WC1E 6BT, UK.

F. Trippetta, Dipartimento di Scienze della Terra, Università degli Studi di Perugia, Piazza dell’Università 1, 06123, Perugia, Italy. 